NBER WORKING PAPER SERIES

\title{
DEVALUATION RISK AND THE SYNDROME OF EXCHANGE-RATE-BASED STABILIZATIONS
}

\author{
Enrique G. Mendoza \\ Martín Uribe \\ Working Paper 7014 \\ http://www.nber.org/papers/w7014 \\ NATIONAL BUREAU OF ECONOMIC RESEARCH \\ 1050 Massachusetts Avenue \\ Cambridge, MA 02138 \\ March 1999
}

We thank Guillermo Calvo, V.V. Chari, Allan Drazen, Greg Huffman, Tim Kehoe, Michael Klein, Pablo Sanguinetti, Sergio Rebelo, Stephanie Schmitt-Grohé and an anonymous referee for valuable comments and suggestions. Comments by seminar participants at the NBER, MIT, NYU, the University of Maryland, the University of Rochester, Queen's University, Universidad Nacional de La Plata (Argentina), the Bank of Canada, the Federal Reserve Banks of Minneapolis and New York, the Bank of Israel, the Bank of Mexico, the IDB, and the IMF are also gratefully acknowledged. The views expressed in this paper are those of the authors and do not reflect those of the National Bureau of Economic Research.

(1) 1999 by Enrique G. Mendoza and Martín Uribe. All rights reserved. Short sections of text, not to exceed two paragraphs, may be quoted without explicit permission provided that full credit, including ${ }^{\mathbb{C}}$ notice, is given to the source. 
Devaluation Risk and the Syndrome of

Exchange-Rate-Based Stabilizations

Enrique G. Mendoza and Martín Uribe

NBER Working Paper No. 7014

March 1999

JEL No. F31, F32, F41, F47

\section{ABSTRACT}

This paper shows that the risk of devaluation can be an important factor accounting for the stylized facts of exchange-rate-based stabilizations. This conclusion follows from studying the quantitative implications of a two-sector equilibrium business cycle model of a small open economy calibrated to Mexico's 1987-1994 stabilization plan. In the model, devaluation risk creates a timevariant interest rate differential that acts as a stochastic tax on money demand, labor supply, investment, and saving. Under incomplete markets, this tax induces endogenous state-contingent wealth effects via fiscal adjustment and suboptimal investment. Devaluation risk entails large welfare costs in this environment.

Enrique G. Mendoza

Department of Economics

Box 90097

Duke University

Durham, NC 27708-0097

and NBER

mendozae@econ.duke.edu
Martín Uribe

Department of Economics

University of Pennsylvania

Philadelphia, PA 19104 


\section{Introduction}

The devaluation of the Mexican peso in December of 1994 marked the collapse of an aggressive stabilization plan introduced six years earlier under the name of "El Pacto de Solidaridad Economica" (The Pact for Economic Solidarity). El Pacto was a variant of an exchange-rate-based stabilization plan which practically fixed the peso-dollar exchange rate while tightening sharply both fiscal and monetary policies. Four significant stylized facts were observed during the period that this stabilization plan was in place: the real exchange rate appreciated sharply and at a varying speed, the economy boomed initially and then fell into recession, external imbalances widened markedly, and the velocity of circulation of money plummeted. Strikingly similar phenomena preceded the devaluations of the Mexican peso in 1954, 1976 and 1982, and have also been documented for a large list of exchange-rate-based stabilization episodes elsewhere (see Helpman and Razin (1987), Kiguel and Liviatan (1992), and Végh (1992)). Exchange-rate-based stabilizations thus seem to exhibit a syndrome defined by these stylized facts. The study of this syndrome has been the focus of an extensive research program seeking to understand the nature of the monetary transmission mechanism behind it.

This paper proposes a transmission mechanism in which the syndrome is a feature of the competitive equilibrium of a monetary economy with incomplete insurance markets, distorted by the risk of collapse of a currency peg. The transmission mechanism operates by allowing devaluation risk to alter the nominal interest rate and money velocity, in an environment in which changes in velocity affect the real sector of the economy because money balances help agents economize transactions costs. The probability of collapse of the peg creates a state-contingent differential between domestic and world interest rates, and this devaluation-risk premium introduces stochastic distortions on money demand, saving, investment, and labor supply. Market incompleteness adds endogenous state-contingent wealth effects to these distortions via suboptimal investment decisions and fiscal cuts induced by the timevariant pattern of the inflation tax. Numerical simulations of the model calibrated to the Mexican experience of 1987-1994 produce macroeconomic dynamics that are roughly consistent with key features of the data.

The existing literature has produced to date four competing theories for explaining the syndrome of exchange-rate-based stabilizations. Dornbusch (1982) and Rodriguez (1982) argued that a fixed 
exchange rate lowers the real interest rate and causes an economic boom because prices are sticky and expectations of inflation adjust slowly. The real interest rate falls because interest parity forces the nominal interest rate to fall, while expectations of inflation remain high. Calvo (1986) proposed the perfect-foresight credibility framework, in which agents anticipate a devaluation and return to high inflation with full certainty. Intertemporal substitution leads consumption to jump to a higher constant level for the duration of the plan, before collapsing in another discrete jump to a lower constant level when the plan fails. ${ }^{1}$ Helpman and Razin (1987) and Drazen and Helpman (1987) examined models in which fiscal policy is not tightened as required by the solvency constraints that determine the sustainability of a peg. They showed that the syndrome can be caused by wealth effects resulting from the timing of changes in the inflation tax or in government expenditures. Finally, Roldós (1995) and Uribe (1997) proposed the supply-side hypothesis. They argued that, even under perfect credibility and price flexibility, a permanent decline in the rate of depreciation of the currency can induce a gradual real appreciation, a boom in domestic absorption, and a deterioration of the current account because it reduces inflation-induced distortions on the relative price of capital and other durable goods.

These theories fit well some elements of the country experiences of the 1970s and 1980s, but they seem at sharply odds with recent experiences. The syndrome of exchange-rate-based stabilizations affected Argentina and Mexico despite sharp declines in price inertia and large fiscal cuts in both countries. Moreover, even though the qualitative predictions of existing theories are consistent with some of the stylized facts, their quantitative performance has been very mixed. They cannot account for the magnitude of observed macroeconomic fluctuations, they fail to explain the high correlation between the real exchange rate and expenditures and the periods of stable real exchange rates in between large appreciations, and they produce real appreciations that are roughly $1 / 8$ of what is observed in the data (see Rebelo and Végh (1996)). ${ }^{2}$

Recent theoretical work sheds light on the origins of some of these empirical shortcomings. First, Calvo and Drazen (1998) showed in a partial-equilibrium setting that uncertainty about the duration

\footnotetext{
${ }^{1}$ Further research added nontraded goods and staggered prices to show that lack of credibility could also trigger gradual real appreciations (see Chapters 15-18 in Calvo (1996)).

${ }^{2}$ Uribe (1997) is an exception that yields a large real appreciation and a large spending boom using a model in which inflation acts as a tax on purchases of intermediate materials as well as on final transactions.
} 
of policy changes and incomplete contigent-claims markets, both issues generally abstracted from in the existing literature, are required in order to account for the observed gradual consumption booms. If Calvo's (1986) model is altered so that the date of a policy reversal is uncertain, producing a gradual consumption boom requires wealth effects resulting from incomplete markets and the unproductive use of government revenue. Still, the Calvo-Drazen framework cannot account for the observed cyclical dynamics because consumption is always nondecreasing, regardless of the time path of the probability of reversal. Second, Uribe (1998a) showed that most of the existing models that study exchange-rate-based stabilizations belong to a large class that features the "price-consumption puzzle." This puzzle implies that the observed high correlation between consumption and the real exchange rate cannot be a property of the equilibrium of models in that class. Along the equilibrium path of these models, the real exchange rate appreciates only if consumption declines.

In this paper we study a stochastic environment similar to the Calvo-Drazen model. There is a major difference, however, because in the framework that we study the currency risk premium establishes an endogenous link between the uncertain duration of the policy regime (i.e., the currency peg) and the variable that drives the distortions on the real economy (i.e., the nominal interest rate). In contrast, the Calvo-Drazen model deals with a trade reform of uncertain duration in which the value of import tariffs while the reform is in place is not affected by the probability of reversal of the trade reform. Our analysis also differs in that we study policy uncertainty in a general-equilibrium context and with the emphasis on the model's quantitative predictions. We assess whether the quantitative features of the syndrome of exchange-rate-based stabilizations can be rationalized as features of equilibrium dynamics in a setting in which agents face devaluation risk.

The numerical analysis applied to the Mexican case shows that the model can account for the price-consumption puzzle, booms followed by recessions that pre-date devaluations, and periods of realexchange-rate stability in between sharp appreciations. The real appreciations we produced are still smaller than measured in the data, but they are 5 times larger than those produced by existing models, and they are also in line with the fraction of the real appreciations that the data suggest can be attributed to currency risk. Moreover, the welfare costs of devaluation risk largely exceed the negligible costs of lack of policy credibility obtained in perfect-foresight studies (see Calvo (1988)). 
The rest of the paper is organized as follows. Section 2 documents empirical regularities of Mexico's 1987-1994 stabilization plan. Section 3 describes the model and the solution method. Section 4 presents the results of the quantitative analysis. Section 5 concludes.

\section{Mexico's 1987-1994 Exchange-Rate-Based Stabilization Plan}

The syndrome of exchange-rate-based stabilizations is described by four stylized facts:

(1) A large appreciation of the real exchange rate that may occur with periods of stability in between rapid appreciations, and is highly correlated with an expansion in private expenditures.

(2) Booms of production and private expenditures, followed by recessions that often predate the collapse of the plans.

(3) A widening of external imbalances that is reversed by the time of the collapse.

(4) A fall in the velocity of circulation of money, followed by a surge around the time of the collapse.

This section documents the above empirical regularities for the Mexican stabilization plan of 1987-1994. Mendoza and Uribe (1997) documented similar stylized facts before the devaluations of the peso in 1954, 1976, and 1982. The section also provides evidence on other elements of the Mexican data that are important for the transmission mechanism of the model proposed in Section 3. Data on national accounts are from the Banco de Información Económica del Instituto Nacional de Estadística, Geografía e Informática, and data on consumer prices, monetary aggregates, interest rates and the exchange rate are from Indicadores Económicos del Banco de México. A detailed data appendix is available from the authors on request.

\subsection{Exchange Rates and Consumer Prices}

Figure 1 plots the monthly evolution of Mexico's real and nominal exchange rates during 19851995. The nominal exchange rate in the left scale is in pesos per dollar, so it increases as the peso depreciates. The real exchange rate index, in the right scale, follows the IMF's convention and is measured as the ratio of Mexico's consumer price index (CPI) over the exchange-rate-adjusted CPI of the United States. An increase in this index indicates a real appreciation of the peso. As Figure 1 shows, Mexico fixed the peso-dollar exchange rate in February of 1988 and kept if fixed for the remainder of that year. This was done jointly with other stabilization measures announced with El Pacto in December 
of 1987, which preceded the economic reforms of the early 1990s. ${ }^{3}$ After 1988 the exchange rate followed a slow-crawling peg system that went through several adjustments. The result was in effect a nearly-fixed exchange rate until the collapse of the peso in December of 1994.

The real exchange rate index is plotted in Figure 1 with February 1988=100, so that the base date coincides with the fixing of the nominal exchange rate. The peso had depreciated sharply in real terms in 1985-1986, so the currency peg started from a low real exchange rate from a historical perspective. The peso appreciated sharply, by about 15 percent, during 1988, and then remained relatively stable during 1989-1990. The appreciation re-emerged in 1991 and continued until it peaked at about 55 percent in March, 1994. Measured from the beginning of the peg to the end (i.e., February, 1988 to December, 1994), the peso appreciated by 45 percent in real terms. At the quarterly frequency consistent with the model we study later, the real appreciation between the first quarter of 1988 and the last quarter of 1994 was 41.5 percent.

Since during the period in question both U.S. CPI inflation and changes in the nominal exchange rate were negligible, compared to Mexico's CPI inflation,, a closer analysis of the Mexican CPI provides key information for understanding the real appreciation of the peso. Figure 2 shows that the real appreciation was driven by a large increase in the domestic relative price of nontradable goods to tradable goods. ${ }^{4}$ The inflation rate for tradables converged rapidly to international levels, but the one for nontradables fell very slowly. This pattern contrasts sharply with evidence from industrial countries showing that real-exchange-rate fluctuations are unrelated to movements in the relative price of nontraded goods (see Engel (1995)).

Figure 3 illustrates the high correlation between private expenditures and the real exchange rate at a quarterly frequency. The cyclical components of private consumption and investment moved together with the real exchange rate from the beginning of the stabilization plan and until expenditures slowed down in 1993, while the real appreciation continued. The correlation coefficient for either consumption or investment and the real exchange rate is about 0.7 , excluding the data from the second quarter of 1993 until the collapse of the plan.

\footnotetext{
${ }^{3}$ Aspe (1993) provides a detailed description of the stabilization plan and the economic reforms.

${ }^{4}$ The CPI for tradables corresponds to durable goods and the one for nontradables corresponds to services. This is roughly consistent with the definitions based on sectoral trade-to-GDP ratios introduced later.
} 
The fact that the real exchange rate and expenditures increased together for $3 / 4$ of the duration of the plan generates the "price-consumption puzzle" identified by Uribe (1998a). This puzzle emerges because along the intertemporal equilibrium path of a certain class of models, which includes the majority of models in the literature on exchange-rate-based stabilizations, the real exchange rate and consumption cannot increase together. The models in this class are those that feature perfect foresight, perfect capital mobility, an exogenous world real interest rate equal to the rate of time preference, and a standard time-separable utility function defined in terms of a linearly homogeneous, concave aggregator of traded and nontraded goods. These features imply that in a fixed-exchange-rate equilibrium the following two conditions must hold: (a) the relative price of nontradables is increasing in the ratio of consumption of tradables to consumption of nontradables, and (b) the marginal utility of consumption of tradables equals the marginal utility of wealth times the monetary distortion (if the model features one). Since perfect foresight and interest parity imply that the marginal utility of wealth and the monetary distortion are constant, conditions (a) and (b) imply that consumption and the real exchange rate move in opposite directions along the equilibrium path.

\subsection{Production, Private Expenditures and Net Exports}

The literature on stabilization in high-inflation countries typically measures booms and recessions using the overall growth of output or consumption between the dates of introduction and abandonment of stabilization plans. We adopted instead the approach of business cycle theory and focused only on the cyclical components of the data. This is important because our model is a model of business cycles, and hence should be assessed using data that excludes long-run trends. In addition, recent stabilization plans have been accompanied by extensive programs of economic reform, as was the case in Mexico. Hence, focusing on raw data can bias the analysis by picking up effects due to the transitional dynamics of economic reforms, as those studied by Fernandez de Córdoba and Kehoe (1999).

Figure 4 plots cyclical components of GDP, private consumption, fixed investment, and the ratio of net exports to GDP using quarterly data for the period 1983:1-1994:4. Given the short sample, the data were filtered using a quadratic trend, testing to confirm that it produced stationary cyclical components. In Mendoza and Uribe (1997) we show that the main features of these cyclical components are robust to the choice of filters. 
Investment, GDP, and consumption experienced significant booms during the first five years of the program, but in 1993 all three fell in recession. Thus, this was a typical stabilization plan in which recession predated currency collapse. Measuring from the first quarter of 1988 to the peak of the cycle in 1992, GDP and consumption increased by 4-5 percentage points, and investment by more than 10 percentage points. The trade balance as a share of GDP worsened from virtual balance in 1988 to a deficit of 6 percent of GDP by 1992, and remained around that level until it was suddenly reversed into a surplus in the first quarter after the devaluation.

It is important to acknowledge that while in our model devaluation risk drives the business cycle, the Mexican business cycle is clearly influenced by other factors -- such as shocks to productivity or the terms of trade -- that may also interact with devaluation risk. Hence, it is worthwhile to try to measure the fraction of Mexican business cycles that can be attributed to devaluation risk alone, and to consider this fraction in assessing the performance of the model. We measured devaluation risk using the nominal interest rate differential between Mexico's peso-denominated treasury certificates CETES and U.S. Tbills, and gauged its contribution to explain Mexico's business cycles using variance decompositions of the VAR model proposed by Calvo and Mendoza (1996). ${ }^{5}$ The interest rate differential explains about 40 percent of the variability of each of the endogenous variables over 24 quarters. Thus, these results suggest that devaluation risk considered in isolation may explain real appreciations of up to 20 percent.

\subsection{Sectoral Features of the Data}

Microeconomic theory predicts that a large change in domestic relative prices as the one documented earlier needs to be accompanied by large shifts in sectoral marginal rates of substitution in consumption and production. Assuming conventional linear-homogeneous functions to represent preferences and technology, these shifts require in turn sectoral shifts in capital-labor ratios and in consumption. Evidence of these shifts is difficult to document because of serious limitations regarding sectoral data. A consistent sectoral breakdown of value added, gross output, investment and consumption is only available at an annual frequency and starting in 1988. This short sample does not allow us to isolate cyclical components, and hence we cannot determine the extent to which changes in

\footnotetext{
${ }^{5}$ Note, however, that the CETE rate was influenced by extensive sterilized intervention during 1990-94. Thus, the CETET-bill differential is at best a noisy measure of market expectations of devaluation.
} 
sectoral data may have reflected structural changes in response to economic reforms. Moreover, data on sectoral capital stocks are not available and sectoral labor allocations are reported only in number of employees per sector. Nevertheless, the available data do show evidence of sectoral shifts in the direction the theory predicts.

We define the tradables and nontradables sectors following the conventional practice of examining the ratios of total trade to gross output in the nine industrial sectors in which total production is divided in the national income accounts. The nontradables sector is composed of the industries for which total trade is less than 5 percent of gross output at current prices. Taking averages over 19881996, the nontradables sector includes: (1) construction, (2) utilities, (3) retailing, restaurants and hotels, (4) financial services and real estate, and (5) social and personal services. The tradables sector consists of (1) agriculture, (2) mining, (3) manufacturing, and (4) transportation, storage and communications.

The ratio of tradables-to-nontradables output at constant prices was nearly unchanged over the period 1988-1994, and averaged 0.89. The ratio of value added across sectors also remained approximately constant at an average near 0.60 . In contrast, labor productivity (i.e., output at constant prices per paid employee) in the tradables sector relative to that in the nontradables sector increased from 0.59 in 1988 to 0.68 in 1994 , while the ratio of employment in the tradables sector relative to the nontradables sector fell from 0.81 to 0.67 in the same period. Hence, there was roughly no change in relative value added across sectors because the reallocation of employment from tradables to nontradables was offset by an increase in relative labor productivity in favor of the tradables sector. Moreover, since further evidence from sectoral data documented in Section 3 favors modeling sectoral production functions as Cobb-Douglas technologies, we conjecture from the efficiency conditions equating sectoral marginal rates of transformation in the Cobb-Douglas case that: (a) the reallocation of labor from tradables to nontradables should have been accompanied by a sectoral reallocation of capital in the same direction, and (b) for the ratio of sectoral GDP to have remained constant, while both capital and labor were being reallocated to the nontradables sector, there must have been an offsetting increase in total factor productivity in the tradables sector.

Sectoral consumption data at 1993 prices, indicate that tradables consumption grew faster than nontradables consumption during the early stages of the plan. Tradables consumption grew 8.5 and 6.6 
percent in 1989 and 1990 respectively, compared to 5.2 and 4.9 percent in the nontradables sector. Surprisingly, however, tradables consumption slowed down more sharply during the cyclical downturn. Tradables consumption grew only 0.3 percent in 1993, compared to growth of 3.9 percent in nontradables consumption, and consumption of manufactures actually declined. For the 1988-1994 period, tradables consumption increased 33.4 percent, compared to 30.3 percent for nontradables. This reallocation of consumption in favor of tradables is qualitatively in line with the movement required for the marginal rate of substitution in consumption to match the increase in the relative price of nontradables.

\subsection{Expenditure Velocity and the Rate of Interest}

The transmission mechanism that drives the model examined in Section 3 operates through the effect of devaluation risk on the nominal interest rate and the velocity of circulation of money. Figure 5 plots the cyclical component of the expenditure velocity of M2 (i.e., consumption plus investment over M2 money balances), which is the relevant measure for money balances used in transactions in Mexico. Velocity followed the U-shaped pattern typical of exchange-rate-based stabilizations during the period 1988-94. Measured from the maximum in early 1989 to the minimum reached in 1993, velocity fell by nearly 40 percentage points.

Evidence on the link between devaluation risk and the interest rate can be documented by examining again the CETES-Tbill interest rate differential. This indicator suggests that devaluation risk was high, at near 60 percent, at the beginning of the program and then declined gradually until the end of 1991, when it stabilized around 15 percent until the devaluation of the peso. However, there is a puzzle in that this indicator reflected only a slight increase in devaluation risk in the months before the devaluation, as the CETE rate did not increase sharply. Other benchmark money-market rates did increase sharply -- the differential between the Mexican interbank interest rate and the CETE rate widened by 10 percentage points before the crisis. Calvo and Mendoza (1996) and Kumhof (1999) proposed models that try to account for this anomaly by modelling banking fragility and central bank sterilization of capital outflows.

\subsection{Fiscal Policy}

The stance of fiscal policy is another key ingredient of the model studied in Section 3. In particular, the model requires temporary reductions in unproductive government expenditures that last for 
the duration of a currency peg. In this account, the Mexican experience is striking. The overall public deficit shifted by nearly 17 percentage points of GDP between 1987 and 1993, going from a deficit of 16 percent of GDP to a surplus of 0.7 percent of GDP. This sharp fiscal contraction reflected in part a marked decline in public debt service that resulted from the decline in the CETE rate after 1988, but it was also supported by a series of large cuts in government absorption that started in 1986. Real government absorption (defined as wages and salaries, goods purchases, federal remittances to state governments, and subsidies to public enterprises) declined by 32 percent between 1986 and 1988 (or the equivalent of 6 percentage points of GDP). Still, these figures underestimate the wealth effects of the fiscal consolidation because they do not capture the efficiency gains that resulted from the extensive program of liquidation and privatization of public enterprises. Through this program, over 450 public enterprises were closed and several others sold. Subsidies to public enterprises fell from a peak of near 4 percent of GDP in 1985 to 1 percent of GDP in 1994.

The above figures also reflect poorly the temporariness of the fiscal adjustment because they exclude large expenses incurred to support the banking system since 1994. Adding financial intermediation by the government, the fiscal position switched from virtual balance to a deficit of 4.5 percent of GDP between 1993 and 1994. By 1998, the fiscal cost of the programs implemented to support the commercial banks since 1995 had escalated to 17 percent of GDP and was still rising.

\section{A Business Cycle Model Driven by Devaluation Risk}

\subsection{Preferences and Technology}

Households are infinitely-lived and maximize the following expected utility function:

$$
\begin{gathered}
E_{0} \sum_{t=0}^{\infty} \beta^{t} \frac{\left[C_{t}\left(1-L_{t}\right)^{\rho}\right]^{1-\sigma}}{1-\sigma} \\
C_{t}=\left[\omega\left(C_{t}^{T}\right)^{-\mu}+(1-\omega)\left(C_{t}^{N}\right)^{-\mu}\right]^{-\frac{1}{\mu}}
\end{gathered}
$$

Households consume a traded good $\left(C_{t}^{T}\right)$ and a nontraded good $\left(C_{t}^{N}\right)$. They supply labor $L_{t}$ and demand leisure $\ell_{t}$ given the normalized time constraint $\ell_{t}=1-L_{t}$. The expectations operator $E_{o}$ applies to the probability of devaluation of the currency, as defined below. Equation (2) characterizes preferences between $C^{T}$ and $C^{N}$ by an isoelastic aggregator, where $1 / 1+\mu$ is the elasticity of substitution between 
tradables and nontradables. Utility from $C$ and $\ell$ is also represented by an isoelastic function, with $1 / \sigma$ denoting the intertemporal elasticity of substitution in consumption and $\rho$ determining the intertemporal elasticity of substitution in leisure for a given value of $\sigma$. $\beta$ is the standard discount factor.

Households maximize utility subject to the following constraints:

$$
\begin{gathered}
\left(1+S\left(V_{t}\right)\right)\left(C_{t}^{T}+p_{t}^{N} C_{t}^{N}+I_{t}\right)=r_{t} K_{t}+w_{t} L_{t}+\frac{m_{t-1}}{1+e_{t}}-m_{t}-B_{t+1}+\left(1+r^{*}\right) B_{t}+T_{t} \\
K_{t+1}=(1-\delta) K_{t}+\varphi\left(\frac{I_{t}}{K_{t}}\right) K_{t}, \\
V_{t}=\frac{C_{t}^{T}+p_{t}^{N} C_{t}^{N}+I_{t}}{m_{t}} \\
\lim _{t \rightarrow \infty} E_{0}\left[\frac{B_{t+1}}{(1+r *)^{t}}\right]=0 .
\end{gathered}
$$

Equation (3) is the budget constraint in units of the traded good. The left-hand side of (3) represents total expenditures in consumption and investment, $I_{t}$, with $p_{t}^{N}$ defining the relative price of nontradables, or the real exchange rate. Following Greenwood (1983) and Kimbrough (1986), we assume that real balances $m$ are held because they help economize transaction costs. Specifically, the unitary transaction cost is assumed to be an increasing function $S$ of the expenditure velocity of money $V$. The unit transaction cost function is assumed to take the form $S=A V^{\prime}$, where $A$ and $\gamma$ are nonnegative parameters. ${ }^{6}$ The right-hand-side of (3) represents the sources of income: factor payments to labor and capital, $K_{t}$, at the rental rates $w_{t}$ and $r_{t}$ respectively, plus changes in the real value of money holdings, minus the net accumulation of real, one-period foreign bonds $B$ that pay the time-invariant real interest rate $r^{*}$, plus lump-sum government transfers $T_{t}$. Since world asset trading is limited to noncontingent bonds, markets of contingent claims are incomplete. PPP in tradable goods holds and foreign prices are assumed to be constant, so that $e$ represents both the inflation rate of tradables and the rate of depreciation of the currency. Real nominal balances are eroded by inflation at the rate $e$.

Equation (4) is the law of motion of the capital stock which embodies capital-adjustment costs as

\footnotetext{
${ }^{6}$ The exponential form of $S$ belongs to the class that yields implications of the transactions costs framework equivalent to those of models with money in the utility function entering in log-separable form (see Feenstra (1986)).
} 
determined by the concave function $\varphi($.$) . Adjustment costs are introduced so as to differentiate capital$ and foreign assets as vehicles of saving and thus avoid the excessive investment variability that would result otherwise (see Mendoza (1995)). To avoid transaction costs in the steady state, we assume that $\varphi(\delta)=\delta$ and that $\varphi^{\prime}(\delta)=1$. Equation (5) is the definition of expenditure velocity. Equation (6) rules out Ponzi games in foreign debt accumulation.

Output of tradable and nontradable goods is produced by competitive, profit-maximizing industries using standard Cobb-Douglas technologies: $Y_{t}^{i}=A^{i}\left(K_{t}^{i}\right)^{a i}\left(L_{t}{ }^{i}\right)^{I-a i}$ for $\mathrm{i}=\mathrm{T}, \mathrm{N}$. This assumption is consistent with strong evidence of constant factor income shares in each of the nine industries that compose the traded and nontraded sectors (as documented later in the calibration exercise). Since factor markets are competitive, factors of production earn their marginal products and the sectoral zero-profits conditions simplify to:

$$
w_{t} L_{t}+r_{t} K_{t}=A^{T}\left(K_{t}^{T}\right)^{\alpha T}\left(L_{t}^{T}\right)^{1-\alpha T}+p_{t}^{N} A^{N}\left(K_{t}^{N}\right)^{\alpha N}\left(L_{t}^{N}\right)^{1-\alpha N}
$$

The equilibrium sectoral allocation of production and the relative price of nontradables will be determined at the tangency point between the production possibilities frontier (PPF) of $Y^{T}$ and $Y^{N}$ and the corresponding isorevenue curve. At equilibrium, the slope of the PPF equals $p^{N}$ and is the key determinant of its time-series variation. It is well-known, however, that if factors of production are homogeneous, and thus can be freely allocated across sectors, the Cobb-Douglas technologies that we assumed produce the Balassa-Samuelson result: $p^{N}$ reflects shifts in sectoral factor productivities and its time-series variation is limited to a fraction of the shift in sectoral capital-labor ratios (the fraction determined by the difference $\alpha \mathrm{T}-\alpha \mathrm{N})$.

Given that, as we document later, $\alpha \mathrm{T}$ and $\alpha \mathrm{N}$ differ by a small margin in the Mexican data, and lacking evidence of the massive productivity changes needed to produce large changes in $p^{N}$ under these conditions, we deviate from the Balassa-Samuelson result by adopting a variant of the specific-factors models developed in the trade literature. These models use transformation curves to represent feasible sectoral factor allocations, considering that factors of production are specific to each sector. For simplicity, we adopt Mussa's (1978) specification, in which capital is sector-specific but labor remains an homogeneous factor. The factor transformation curves are:

$$
K_{t}=\kappa\left(K_{t}^{T}, K_{t}^{N}\right) \quad \text { and } \quad L_{t}=L_{t}^{T}+L_{t}^{N}
$$




\subsection{Equilibrium and Numerical Solution Method}

The first-order conditions of the maximization problems of households and firms can be combined in the following set of optimality conditions:

$$
\begin{aligned}
& \lambda_{t} h\left(i_{t}\right)=\beta^{t} \omega\left(\frac{C_{t}^{T}}{C_{t}}\right)^{-(1+\mu)} C_{t}^{-\sigma}\left(1-L_{t}^{N}-L_{t}^{T}\right)^{p(1-\sigma)} \\
& p_{t}^{N}=\frac{1-\omega}{\omega}\left(\frac{C_{t}^{N}}{C_{t}^{T}}\right)^{-(1+\mu)} \\
& \frac{\rho\left(C_{t}^{T}+p_{t}^{N} C_{t}^{N}\right) h\left(i_{t}\right)}{\left(1-L_{t}^{N}-L_{t}^{T}\right)}=(1-\alpha T) A^{T}\left(\frac{K_{t}^{T}}{L_{t}^{T}}\right)^{\alpha T} \\
& \lambda_{t}\left[1-S^{\prime}\left(V_{t}\right) V_{t}^{2}\right]=E_{t} \frac{\lambda_{t+1}}{1+e_{t+1}} \\
& \lambda_{t}=E_{t} \lambda_{t+1}(1+r *) \\
& \frac{\lambda_{t} h\left(i_{t}\right)}{\varphi^{\prime}\left(\frac{I_{t}}{K_{t}}\right)}=E_{t} \lambda_{t+1}\left[\frac{\alpha T A^{T}}{\kappa_{1}\left(K_{t+1}^{T}, K_{t+1}^{N}\right)}\left(\frac{K_{t+1}^{T}}{L_{t+1}^{T}}\right)^{-(1-\alpha T)}+\frac{h\left(i_{t+1}\right)}{\varphi^{\prime}\left(\frac{I_{t+1}}{K_{t+1}}\right)}\left[(1-\delta)+\varphi\left(\frac{I_{t+1}}{K_{t+1}}\right)-\varphi^{\prime}\left(\frac{I_{t+1}}{K_{t+1}}\right) \frac{I_{t+1}}{K_{t+1}}\right]\right] \\
& (1-\alpha T) A^{T}\left(\frac{K_{t}^{T}}{L_{t}^{T}}\right)^{\alpha T}=(1-\alpha N) A^{N}\left(\frac{K_{t}^{N}}{L_{t}^{N}}\right)^{\alpha N} p_{t}^{N} \\
& \alpha T A\left(\frac{K_{t}^{T}}{L_{t}^{T}}\right)^{-(1-\alpha T)}=\alpha N A^{N}\left(\frac{K_{t}^{N}}{L_{t}^{N}}\right)^{-(1-\alpha N)} p_{t}^{N}\left[\frac{\kappa_{1}\left(K_{t}^{T}, K_{t}^{N}\right)}{\kappa_{2}\left(K_{t}^{T}, K_{t}^{N}\right)}\right]
\end{aligned}
$$

In these expressions, $h\left(i_{t}\right) \equiv l+V\left(i_{t}\right)+V\left(i_{t}\right) S^{\prime}\left(V\left(i_{t}\right)\right)$ denotes the marginal transactions cost of private expenditures, where $1+i_{t}$ is the gross, risk-free domestic nominal interest rate (i.e., the reciprocal of the period- $t$ price of a nominal bond that pays 1 unit of domestic currency in $t+1)$. We refer to $h\left(i_{t}\right)$ as the model's monetary distortion. $\quad V$ is expressed as a function of $i$ because it follows from (12) and (13) that in equilibrium the following condition holds:

$$
S^{\prime}\left(V_{t}\right) V_{t}^{2}=\frac{i_{t}}{\left(1+i_{t}\right)}
$$


Given the convexity of $\mathrm{S}$, it is straightforward to show that both $V$ and $h$ are increasing in $i$.

The optimality conditions are easy to interpret. Equation (9) determines the marginal utility of wealth. Equation (10) equates the marginal rate of substitution between $C^{T}$ and $C^{N}$ to $p^{n}{ }^{7}$ Equation (11) represents the optimal consumption-leisure tradeoff. Equations (12)-(14) are Euler equations for real balances, foreign assets, and aggregate capital respectively. Equations (15)-(16) reflect the equality of sectoral marginal products of $L$ and $K$ respectively.

The government issues money, from which it collects seigniorage, makes unproductive purchases of $G$ units of traded goods, and makes transfer payments to households. We assume that a fraction $\eta$ of the inflation tax revenue is allocated to $G$, and the rest of the government revenue is rebated as a lump sum transfer. Hence the government budget constraint is:

$$
G_{t}+T_{t}=m_{t}-\frac{m_{t-1}}{1+e_{t}}, \quad \text { with } \quad G_{t}=\eta\left(\frac{e_{t}}{1+e_{t}} m_{t-1}\right), \quad 0 \leq \boldsymbol{\eta} \leq 1 .
$$

This constraint induces an endogenous tightening of fiscal policy after an exchange-rate-based stabilization plan begins because of the sharp decline in seigniorage that follows. Note in particular that, for as long as the plan is in place, the inflation tax is eliminated leading to a sharp cut in government expenditures. The temporariness of the fiscal adjustment is also endogenous, since a devaluation implies a sudden surge in seigniorage and a return to permanently-higher inflation. This endogenous, statecontingent fiscal adjustment is analogous to the one introduced by Calvo and Drazen (1998).

The market-clearing conditions of each sector are the following:

$$
\begin{gathered}
C_{t}^{N}=A^{N}\left(K_{t}^{N}\right)^{\alpha N}\left(L_{t}^{N}\right)^{1-\alpha N} \\
C_{t}^{T}+I_{t}+G_{t}=A^{T}\left(K_{t}^{T}\right)^{\alpha T}\left(L_{t}^{T}\right)^{1-\alpha T}-B_{t+1}+\left(1+r^{*}\right) B_{t}-m_{t} V_{t} S\left(V_{t}\right)
\end{gathered}
$$

We examine the equilibrium dynamics of this model for a policy experiment in which the government implements an exchange-rate-based stabilization plan at date 0 but agents attach some positive probability to the event that the plan may be abandoned. Specifically, at $t=0$ the government sets $e_{o}=0$ and announces the stabilization plan. Agents attach a time-dependent, conditional probability

\footnotetext{
${ }^{7}$ Uribe (1998a) derived the price-consumption puzzle from expressions like (9)-(10), assuming perfect-foresight and a fixed exchange rate. In this case, $\lambda$ and $i$ are time-invariant, so the right-hand-side of (9) is constant, and by (10) $p^{n}$ is increasing in $C^{T} / C^{N}$. These results, and the fact that $C$ is linear-homogenous in $\left(C^{T}, C^{N}\right)$ imply that $C$ is decreasing in $p^{n}$.
} 
$z_{t}=\operatorname{Pr}\left[e_{t+1}>0 \mid e_{t}=0\right]$, defined by the hazard rate function $Z(t)$, to the devaluation of the currency. As in Calvo and Drazen (1998), $Z$ is exogenous and the reversal of the stabilization plan is an absorbent state (i.e., $\operatorname{Pr}\left[e_{t+1}>0 \mid e_{t}>0\right]=1$ ). We also adopt their assumption that the policy variable has only two states. Hence, the depreciation rate is either $e_{t}=0$ or $e_{t}=e>0$, with $e$ the same regardless of the date in which the devaluation occurs. The post-collapse value of $e$ is identical to its pre-stabilization value, which is the standard assumption of the credibility models of exchange-rate-based stabilization. Moreover, at some future date $J \leq \infty$ policy uncertainty is resolved, so if the stabilization plan is in place at date $J-1$, then at $J$ the plan either fails permanently with probability $\Pi$ or succeeds permanently with probability 1-П.

The competitive equilibrium of the model is given by the sequences of state-contingent allocations and prices $\left\{\mathrm{C}_{t}^{\mathrm{T}}, \mathrm{C}_{\mathrm{t}}^{\mathrm{N}}, \lambda_{\mathrm{t}}, \mathrm{L}_{\mathrm{t}}^{\mathrm{T}}, \mathrm{L}_{\mathrm{t}}^{\mathrm{N}}, \mathrm{K}_{\mathrm{t}}^{\mathrm{T}}, \mathrm{K}_{\mathrm{t}}^{\mathrm{N}}, \mathrm{K}_{\mathrm{t}+1}, \mathrm{I}_{\mathrm{t}}, \mathrm{m}_{\mathrm{t}}, \mathrm{i}_{\mathrm{t}}, \mathrm{V}_{\mathrm{t}}, \mathrm{p}_{\mathrm{t}}^{\mathrm{N}}, \mathrm{G}_{\mathrm{t}}, \mathrm{B}_{\mathrm{t}+1}\right\}_{\mathrm{t}=0}{ }^{\infty}$ such that equations (3)-(20) hold for $t=0, \ldots \infty$. Since the state $e_{t}>0$ is absorbent, each period the economy can either: (a) follow the optimal path corresponding to the state in which $e_{t}=0$ at $t$, with $z_{t}$ governing the probability that $e_{t+1}=e$, or (b) if $e_{t}=e$ at $t$ there is a once-and-for-all switch to a perfect-foresight path corresponding to that constant rate of depreciation. The solution method draws on Uribe (1998b) and it is a log-linear adaptation of the near-exact solution method used in the working paper version of this paper (see the appendix to Mendoza and Uribe, (1997)). In that paper, we developed a near-exact solution method for a model that featured perfect-foresight equilibria with constant depreciation rates in which the trajectories for consumption and leisure were constant. This property was a consequence of the assumption that the nontraded sector employed only labor and the traded sector employed only capital. In contrast, in the model we study here both sectors use capital and labor. As a result, all endogenous variables, except for the marginal utility of consumption, display time-dependent paths under perfectforesight. The method we use also keeps track of the state-contingent evolution of wealth by taking advantage of the two-state absorbent Markovian specification of uncertainty, and addresses the dependency on initial conditions of the model's deterministic stationary equilibrium (which is typical of open-economy models with noncontingent bonds and standard preferences). ${ }^{8}$

\subsection{Calibration}

\footnotetext{
${ }^{8}$ If capital were homogenous across sectors, the dependency on initial conditions can be addressed by solving directly the two-point boundary problem. With sector-specific capital, however, it is more efficient to circumvent the problem by allowing $r^{*}$ to be a function of the stock of foreign debt with a negligible elasticity.
} 
We propose below benchmark parameter values for the numerical analysis. The values of most parameters are determined using Mexican data, but there are a few key parameters, on which there is limited empirical evidence. The implications of varying these paramateres will be illustrated later by conducting sensitivity analysis.

a) Velocity and Money demand: Given $S=A V^{\prime}$, equation (17) implies: $V_{t}=\left(i_{t} / 1+i_{t}\right)^{1 /(1+;)}(\gamma A)^{-1 /(1+;)}$. Since $V \equiv(C+I) / m$, it follows therefore that the model predicts a log-linear relationship between money demand, expenditures, and $i /(1+i)$. The elasticity of money demand with respect to its opportunity cost is $-1 /(1+\gamma)$ and the elasticity with respect to expenditure equals one. These predictions are strongly supported by the findings of recent econometric studies of the demand for M2 in Mexico before the 1994 crash (see Kamin and Rogers (1996) and Calvo and Mendoza (1996)). These studies used GDP, instead of private expenditures, as an explanatory variable of money demand but we examined the performance of similar econometric models replacing GDP with $(\mathrm{C}+\mathrm{I})$. We found that the existing results are generally robust to this change. In particular, we obtained the same interest elasticity of money demand, -0.16 (with a standard error of 0.027), and we found strong evidence of a long-run, unitary expenditures elasticity as well as a cointegrating relationship between real M2, $i /(1+i)$, and expenditures. ${ }^{9}$ Our estimate of the interest elasticity implies that $1 /(1+\gamma)=-0.16$ so we set $\gamma=5.25$. We then set $A=0.548$ by solving from $V_{t}=\left(i / 1+i_{t}\right)^{1 /(1+i)}(\gamma A)^{-1 /(1+\gamma)}$ setting $V=0.374 / 4$, which is the quarterly equivalent of the 1987 ratio (C+I)/M2 in the Mexican data, and setting $i$ to 30 percent per quarter. The latter was determined by setting $\mathrm{r}^{*}=0.065$ per year and by taking Mexico's observed tradables inflation rate of 170 percent per year (an average of annual inflation rates for the three-month period ending in February, 1988, when the exchange rate was fixed), and combining these figures with the assumptions of perfect capital mobility, PPP in tradables, and interest rate parity.

b) Preferences: The risk aversion coefficient, $\sigma$, is set at 5 , which is the median of existing estimates for developing economies that range between 1.25 and 10 (see Reinhart and Vegh (1995)). $\sigma=5$ is also the lower-bound of estimates obtained for Mexico by Reinhart and Vegh (1994). The elasticity of substitution between $C^{\mathrm{T}}$ and $\mathrm{C}^{\mathrm{N}}$ is set to $1 /(1+\mu)=0.76$, reflecting the developing-country estimates

\footnotetext{
${ }^{9}$ This implies that the money demand regression can be efficiently estimated using as independent variables the logarithms of $i /(1+i)$ and lagged $\mathrm{V}$, the annual change in $i /(1+i)$, and seasonal dummies (see Kamin and Rogers (1996)).
} 
produced by Ostry and Reinhart (1992). For simplicity, the rate of time preference is assumed to be identical to $r^{*}$, so that $\beta=\left(1+r^{*}\right)^{-1}$. The parameter $\omega$ is set at a value such that, given the units in which each of the two goods are measured, the steady-state share of consumption of nontradables in GDP is 0.56. The leisure exponent in utility is set imposing the standard real-business-cycle restriction that in steady state households spend 20 percent of their time working. This implies $\rho=1.5433$.

c) Technology: Values of technology parameters were determined using national accounts data on sectoral factor payments and value added. The shares of labor income in value added were set to $1-\alpha^{\mathrm{T}}=$ 0.26 and $1-\alpha^{\mathrm{N}}=0.36$, which are averages over the period for which data are currently available (19881996). ${ }^{10}$ The labor income shares of each of the 9 industries in which GDP is decomposed fluctuated very little over the sample period, suggesting that the Cobb-Douglas representation of sectoral value added is a reasonable approximation. The quarterly rate of depreciation of the capital stock, $\delta$, was set at 1 percent, which, together with the other parameters of the model implies a steady-state share of gross investment in GDP of 18 percent, consistent with Mexican data. This approach to calibrate $\delta$ to mimic the observed investment rate follows the calibration guidelines of Cooley and Prescott (1995).

The remaining technology parameters involve capital adjustment costs and the sectoral capital transformation curve. Since these parameters cannot be directly related to Mexican data or existing econometric studies, we produced benchmark parameters aiming to match those features of the data that these parameters are likely to affect most directly. With regard to the capital-adjustment-cost function, the simulations require a value for the elasticity of investment with respect to Tobin's Q, which is given by $-1 /\left[\delta \varphi^{\prime \prime}(\delta)\right]$. We set this elasticity so that the investment boom in the model is roughly consistent with Mexican data. The implied value is $1 / 3$. For the capital transformation curve, we set the elasticity of substitution between $\mathrm{K}^{\mathrm{T}}$ and $\mathrm{K}^{\mathrm{N}}, \xi \equiv\left(\kappa_{12} \kappa\right) /\left(\kappa_{1} \kappa_{2}\right) \leq 0$, equal to -0.1 , so as to match the observed increase in $p^{n}$ that according to the variance decomposition of the data could be attributed to devaluation risk (at most 20 percent).

d) Policy variables: The fraction of the inflation tax assigned to government purchases, $\eta$, is set to $2 / 3$ so

\footnotetext{
${ }^{10}$ The fact that the labor shares are about $1 / 2$ those in industrial countries raises doubt about the accuracy of Mexican data, although Mendoza (1995) shows that several developing countries report similar figures. We also argue below that for our key results, the relative values of the shares is more important than their absolute values. Developing and industrial country data are consistent in that labor shares do not differ sharply across sectors (see Mendoza (1995)).
} 
$-18-$

as to roughly match the observed share of government absorption in GDP (as defined in Section 2) at the end of 1987 (i.e., 18.5 percent). The rate of depreciation of the currency to which the economy switches when the program fails is set so that at the time of the collapse the inflation rate of tradables returns to its pre-stabilization peak of 170 percent per annum.

e) Hazard rate function: The stochastic process driving devaluation probabilities is treated as analogous to the exogenous disturbances that drive a real-business-cycle model. Thus, we calibrate $Z$ to the existing empirical evidence on the time path of devaluation probabilities. Several studies provide strong evidence indicating that devaluation probabilities follow a J-shaped time path, both in Mexico and in many fixedexchange-rate regimes across developing countries. Blanco and Garber (1986) estimated J-shaped devaluation probabilities for the Mexican peso before the devaluations of 1976 and 1982 using a Krugman-style model of balance-of-payments crises. The probability of collapse was 0.2 early in 1977, declining to near zero in about a year, rising slowly in 1978-79, and rising rapidly to about 0.4 before the 1982 devaluation. Goldberg (1994) extended the Blanco-Garber analysis to the 1980-86 period and found that the probability of collapse in early 1982 was in excess of 0.9. Klein and Marion (1997) used logit analysis to identify factors that influence the duration of currency pegs in a panel of monthly data for 17 countries over the 1957-91 period. They found strong evidence showing that sharp real appreciations predate devaluations and that devaluation probabilities are J-shaped. Probabilities of collapse one month before a devaluation are as high as 0.89 , with $1 / 10$ of the estimates higher than 0.55 . In light of this evidence, we adopted a J-shaped hazard rate set below 0.5 when the program begins, falling to zero, and rising to about 0.8 prior to the collapse. We also set $J=24$, in line with the six-year duration of Mexican currency pegs observed since 1970 and assume as a benchmark case that if the program survives until period $J$-1, then in period $J$ it is abandoned for sure, that is, $\Pi=1$.

\section{Quantitative Implications of the Model}

\subsection{Intuition of The Model's Transmission Mechanism}

We develop some intuition for understanding the model's monetary transmission mechanism before examining the results of the numerical simulations. The key distortion that devaluation risk introduces in the model can be illustrated by rewriting equation (17) as follows:

$$
S^{\prime}\left(V_{t}^{L}\right)\left(V_{t}^{L}\right)^{2}=\frac{r^{*}}{\left(1+r^{*}\right)}+\left[\frac{\lambda_{t+1}^{H}}{E_{t}\left[\lambda_{t+1} \mid e_{t}=0\right]}\right]\left(\frac{z_{t} e}{(1+e)\left(1+r^{*}\right)}\right)
$$


This equation is the equilibrium condition for the choice of $m_{t}$ from the perspective of any date $t$ in which the stabilization plan is in place, and hence the depreciation rate is at its low state $e_{\mathrm{t}}^{\mathrm{L}}=0$ with the corresponding state-contingent choice for velocity $V^{L}$. In equilibrium, the marginal benefit of holding an extra unit of real balances, in the left-hand-side of (21), equals the opportunity cost of holding money in the right-hand-side. Thus, the term in the right-hand-side is also the nominal interest rate factor $i_{t} /\left(1+i_{t}\right)$.

Equation (21) shows that the domestic nominal interest rate differs from the world interest rate because of the presence of currency risk in holding domestic money (recall that world inflation is assumed to be zero, so $r *$ in (21) denotes both the real and nominal world interest rates). In particular, the interest rate differential reflects a distortion that takes the form of a risk-adjusted covered interest parity condition. The second term in the right-hand-side of (21) shows that the time path of this distortion is governed by two effects: (a) changes in the expected rate of depreciation of the currency $z_{t} e$ and (b) fluctuations in the marginal utility of wealth in the high-depreciation-rate state $\lambda_{t+1}{ }^{\mathrm{H}}$ relative to its conditional mean $\mathrm{E}_{\mathrm{t}}\left[\lambda_{t+1} \mid e_{t}=0\right]$. The first effect is exogenous to the model and corresponds to the standard expected-depreciation premium under risk neutrality. The second effect, in contrast, is endogenous and reflects the risk-averse nature of households and the incompleteness of insurance markets (without either of these assumptions $\left.\lambda_{t+1}{ }^{H} / E_{t}\left[\lambda_{t+1} \mid e_{t}=0\right]=1\right)$. Moreover, we can also infer that the wealth effect enlarges the interest rate differential (i.e., $\lambda_{t+1}{ }^{H} / \mathrm{E}_{\mathrm{t}}\left[\lambda_{\mathrm{t}+1} \mid \mathrm{e}_{\mathrm{t}}=0\right]>1$ ) because a return to high inflation and high unproductive government purchases reduces wealth (which increases $\lambda$ ).

The interest rate distortion affects the real sector via the monetary distortion $h(i)$, which has a direct effect on the margins of decision-making that determine saving, investment, and labor supply. By combining equations (9) and (13), using the assumption that $\beta\left(1+r^{*}\right)=1$, we can show that $h(i)$ acts as a stochastic saving tax by altering the intertemporal relative price of $\mathrm{C}^{\mathrm{T}}$ :

$$
U_{C^{T}}\left(C_{t}^{T}, C_{t}^{N}, \ell_{t}\right)=E_{t}\left[U_{C^{T}}\left(C_{t+1}^{T}, C_{t+1}^{N}, \ell_{t+1}\right)\left(\frac{h\left(i_{t}\right)}{h\left(i_{t+1}\right)}\right)\right]
$$

Since $h(i)$ is increasing in $i$ and $i$ increases with the conditional probability of devaluation, the effective tax on saving (in terms of units of $C^{T}$ ) rises (falls) when the probability of devaluation rises (falls). Thus, an increasing (decreasing) probability of devaluation induces an intertemporal substitution effect that favors a decreasing (increasing) tradables consumption path. 
The fact that devaluation risk drives a wedge between $i$ and $i^{*}$ while the exchange rate is fixed is an important feature that distinguishes this model from the perfect-foresight credibility models based on Calvo (1986). Consumption booms in these models result from an intertemporal substitution effect reflected in the perfect-foresight variant of condition (22) that holds only between the last period of a currency peg and the first post-collapse period. Between any two periods $t$ and $t+1$ in which the exchange rate is fixed there is no substitution effect because under perfect foresight $i_{t} \approx r^{*}$, and hence the intertemporal relative price of consumption equals 1 . Moreover, the size of the substitution effect that hits at the date of the collapse is also different because, while the post-collapse nominal interest rate in our model is the same as in the perfect foresight models (i.e. the interest rate jumps to $i \approx r^{*}+e$ when a devaluation occurs), the pre-collapse interest rate in our model is state-contingent and depends on $z_{t .}$

Devaluation risk also introduces state-contingent wealth effects because of the assumed market incompleteness. The wealth and substitution effects operate jointly in a similar fashion as in Calvo and Drazen (1998). If the inflation tax were fully rebated to households, the distortions affecting the model would be limited to intertemporal substitution effects. For as long as it lasts, a currency peg represents a sequence of favorable relative price shocks. At each date $t$ in the fixed-exchange-rate period, agents attach a certain probability to the scenario that prices at $t+1$ will rise with a devaluation, and hence have an incentive to over-consume. As $t+1$ arrives they realize they over-consumed and adjust consumption accordingly. In contrast, when the inflation tax finances $G$, the intertemporal substitution effect can be offset by a wealth effect. Each period that the peg survives, permanent income rises by the amount of the foregone unproductive expenditures. If the elasticity of intertemporal substitution is sufficiently low, the wealth effect dominates and consumption rises over time.

The model's optimality conditions can be re-arranged to show that devaluation risk also imposes stochastic taxes on investment and labor supply via the monetary distortion:

$$
\begin{aligned}
& U_{C^{T}}\left(C_{t}^{T}, C_{t}^{N}, \ell_{t}\right)\left[\varphi^{\prime}\left(\frac{I_{t}}{K_{t}}\right)\right]^{-1}= \\
& E_{t} \frac{U_{C^{T}}\left(C_{t+1}^{T}, C_{t+1}^{N}, \ell_{t+1}\right)}{h\left(i_{t+1}\right)}\left[\frac{\alpha T A^{T}}{\kappa_{1}\left(K_{t+1}^{T}, K_{t+1}^{N}\right)}\left(\frac{K_{t+1}^{T}}{L_{t+1}^{T}}\right)^{-(1-\alpha T)}+\frac{h\left(i_{t+1}\right)}{\varphi^{\prime}\left(\frac{I_{t+1}}{K_{t+1}}\right)}\left[(1-\delta)+\varphi\left(\frac{I_{t+1}}{K_{t+1}}\right)-\varphi^{\prime}\left(\frac{I_{t+1}}{K_{t+1}}\right) \frac{I_{t+1}}{K_{t+1}}\right]\right]
\end{aligned}
$$




$$
\frac{U_{\ell}\left(C_{t}^{T}, C_{t}^{N}, \ell_{t}\right)}{U_{C^{T}}\left(C_{t}^{T}, C_{t}^{N}, \ell_{t}\right)}=\frac{(1-\alpha T) A^{T}}{h\left(i_{t}\right)}\left(\frac{K_{t}^{T}}{L_{t}^{T}}\right)^{\alpha T}
$$

The monetary distortion taxes the marginal product of newly installed capital at a rate of $1 / h\left(i_{t+1}\right)$ and the marginal product of current labor supply at a rate of $1 / h\left(i_{t}\right)$.

Equations (23) and (24) also embody the so-called "supply side" distortions induced by the transaction costs setup under perfect foresight (see Uribe (1997) and Lahiri (1996)). These distortions affect both transitional dynamics and the steady state because a once-and-for-all disinflation under perfect foresight would cut transaction costs permanently, thereby releasing resources to finance a permanently higher capital stock and reducing permanently the wedge between the real wage and the marginal rate of substitution between consumption and leisure.

The intuition for the behavior of the real exchange rate can be derived by combining equations (15) and (16) to solve for $p^{N}$ as the slope of the PPF of tradables and nontradables and taking logs of the resulting expression (assuming for simplicity that $\kappa\left(K^{\mathrm{T}}, K^{\mathrm{N}}\right)=\left[\left(\mathrm{K}^{\mathrm{T}}\right)^{-v}+\left(\mathrm{K}^{\mathrm{N}}\right)^{-v}\right]^{-1 / v}$, where $\xi=1 /(1+v)$ and $\left.v \leq 0\right)$ :

$$
\operatorname{Ln}\left(p_{t}^{N}\right)=\left[\operatorname{Ln}\left(\left(\frac{1-\alpha T}{1-\alpha N}\right)^{1-\alpha T}\left(\frac{\alpha T}{\alpha N}\right)^{\alpha T}\left(\frac{A^{T}}{A^{N}}\right)\right)+(\alpha T-\alpha N) \operatorname{Ln}\left(\frac{K_{t}^{N}}{L_{t}^{N}}\right)\right]-\frac{\alpha T}{\xi} \operatorname{Ln}\left(\frac{K_{t}^{N}}{K_{t}^{T}}\right)
$$

This expression illustrates how sector-specific capital alters the determination of $p^{N}$ relative to the Balassa-Samuelson result. The Balassa-Samuelson result is the term in square brackets and shows that the time series variation of $p^{N}$ can be expressed as the fraction $\alpha \mathrm{T}-\alpha \mathrm{N}$ of the change in the capital-labor ratio of the nontradables sector. Sector-specific capital modifies this result by introducing changes in $p^{N}$ as a result of sectoral re-allocations of capital, even if capital-labor ratios remain constant or if $\alpha \mathrm{T}=\alpha \mathrm{N}$. The elasticity of the real exchange rate with respect to $\mathrm{K}^{\mathrm{N}} / \mathrm{K}^{\mathrm{T}}$ is given by $-\alpha \mathrm{T} / \xi$, which is non-negative because $0 \leq \alpha \mathrm{T} \leq 1$ and $\xi \leq 0$. Note, however, that (25) is not a closed-form solution, but only a condition that reflects efficient factor allocation.

It is also important to note that the monetary distortion is built not to affect directly the slope of the PPF in the right-hand-side of (25), or the marginal rate of substitution between $\mathrm{C}^{\mathrm{T}}$ and $\mathrm{C}^{\mathrm{N}}$ in the lefthand-side of (10). Hence, the real exchange rate is influenced by the monetary distortion only indirectly 
through its effects on the capital accumulation process, labor supply, and the sectoral allocation of capital, labor and consumption.

\subsection{Benchmark Simulation}

Figure 6 plots the state-contingent equilibrium dynamics for the benchmark simulation as percent deviations from the pre-stabilization steady state, together with the hazard rate function. The continuous lines represent equilibrium paths for the state of nature in which the exchange rate remains fixed. The dotted lines indicate allocations to which the model jumps on impact when a devaluation occurs on the corresponding date in the horizontal axis.

The benchmark simulation produces cyclical dynamics for GDP, velocity, net exports, aggregate and sectoral consumption, the real exchange rate, investment, and labor. ${ }^{11}$ These dynamics are roughly in line with several of the stylized facts documented in Section 2:

(1) The model produces boom-recession cycles in GDP, consumption, and investment with recessions that pre-date the devaluation. The magnitude of the booms in GDP and nontradables consumption are roughly consistent with the empirical evidence. The investment boom is also consistent with the data but this result reflects the criterion used to calibrate the investment elasticity of Tobin's Q.

(2) Consumption and the real exchange rate are highly, but not perfectly, correlated. This result shows that the price-consumption puzzle can be solved by introducing uncertainty and incomplete markets. These features make both the monetary distortion and the marginal utility of wealth contingent on the state of nature, allowing currency risk to yield equilibrium dynamics in which the relative price of nontradables and consumption increase at the same time. There is a sharp real appreciation of about 18 percent in the first two years of the program. The real exchange rate then stabilizes and begins to depreciate gradually, but still ends appreciated by about 13 percent even if the stabilization plan lasts its maximum duration of 6 years.

(3) The trade balance worsens markedly on impact, continues to decline for the first two years of the program and then displays a gradual recovery. Still, even if the plan does not collapse until it reaches its maximum duration, net exports remain 12 percent below the pre-stabilization level.

(4) Velocity falls sharply in a sudden jump of 10 percent when the program begins, and continues to fall

\footnotetext{
${ }^{11}$ Net exports exclude public absorption, which remains constant for the duration of the currency peg.
} 
gradually for the first 10 quarters of the program, before it begins to rise gradually for the rest of the duration of the peg. Note that velocity always switches to its pre-stabilization value whenever the currency is devalued. This follows from equation (17), and the assumption that the rate of depreciation of the currency post-collapse is identical to its pre-stabilization value.

The dynamics plotted in Figure 6 are the result of the tax-like distortions that currency risk imposes on money velocity, investment, saving and the supply of labor. Since in equilibrium $i$ and $h(i)$ can be expressed as increasing functions of $V$, it follows that both the nominal interest rate and the monetary distortion follow similar U-shaped paths. Thus, the taxes on capital and labor income fall for the first 10 quarters of the peg, and rise for the remainder of the peg. The tax on saving, which is the ratio $h\left(i_{t}\right) / h\left(i_{t+1}\right)$, also falls for the first 10 quarters and increases during the latter stages of the peg. Consumption, labor supply, and investment expand while the taxes decline and contract during the period in which the taxes increase.

This benchmark simulation suggests that the quantitative implications of the tax-like distortions induced by devaluation risk can be significant, and this is an important departure from the findings of other quantitative studies of the syndrome of exchange-rate-based stabilizations. For example, Reinhart and Végh (1995) simulated Calvo's (1986) endowment-economy model given observed temporary declines in nominal interest rates, duration of stabilization plans, and econometric estimates of $\sigma$. They found that for the model to predict realistic consumption booms, the fall in interest rates needed to be significantly larger than observed in the data. Even if this were the case, consumption would only jump on impact as the stabilization begins, and remain constant until it collapses when the program is abandoned, so cyclical dynamics and the price-consumption puzzle could not be accounted for. Rebelo and Végh (1996) simulated variants of a two-sector, general-equilibrium model under perfect foresight and found that consumption booms and real appreciations are underestimated by a large margin. In their best-case scenario, which requires sticky prices, the real exchange rate appreciates gradually and peaks at 5 percent. Consumption of tradables (nontradables) rises on impact also by 5 percent and then rises (falls) gradually until it collapses with the devaluation. The real appreciation is driven by a counterfactual fall in the supply of nontradables that begins immediately after the announcement of the plan, and the price-consumption puzzle remains unresolved. The jumps in 
consumption typical of Calvo's model do not emerge because of the combination of (a) capital adjustment costs, (b) the presence of investment in transaction costs, (c) perfect sectoral labor mobility with Cobb-Douglas technologies, and (d) the utility function proposed by Greenwood, Hercowitz and Huffman (1988), which eliminates the wealth effect on labor supply. ${ }^{12}$ However, investment and real balances still display sudden jumps, and without (c) and (d) the discrete jumps re-emerge.

The 18-percent real appreciation in the benchmark simulation is more than 3 times larger than those produced by perfect-foresight models. As we show below, the larger appreciation in our model results from the combination of incomplete markets with temporary fiscal cuts. In the perfect-foresight studies cited above, government revenue is fully rebated to the public, so there is no temporary cut in government expenditures while the stabilization plan is in place. The assumption that stabilization is accompanied by substantial fiscal retrenchment, and the perception that this fiscal adjustment may be as temporary as the currency peg, seem more consistent with the stance of fiscal policy observed in Mexico.

The real appreciation produced by the benchmark simulation is still less than $1 / 2$ the full real appreciation in the Mexican data, even though it is close to the 20-percent appreciation that the VAR analysis attributed to devaluation risk. Hence, our framework still leaves unexplained an important fraction of the real appreciation. This is not surprising because large real appreciations can also result from major economic reforms, such as those in the areas of domestic market deregulation, privatization, and trade and financial liberalization undertaken in Mexico during 1987-1884. Gonzales de Córdoba and Kehoe (1999) show in an exercise applied to Spain that, as long as production technologies feature sector-specific factors, the liberalization of capital flows alone can produce a large real appreciation.

\subsection{Sensitivity Analysis}

We document next the results of sensitivity analysis. This analysis identifies the features of the model that are critical for producing the results of the benchmark simulation. In addition, the analysis shows that two important drawbacks of the benchmark simulation (i.e., that it cannot mimic the observed pattern of a stable real exchange rate in between periods of sharp appreciation, and that it produces a boom in tradables consumption larger than observed in the data) can be accounted for with plausible parameterizations of the model.

\footnotetext{
${ }^{12}$ Rebelo and Végh (1996) found that labor exhibited a counter-factual fall with the standard isoelastic utility function.
} 
$-25-$

Figure 7 summarizes the sensitivity analysis by presenting plots for the dynamics of the real exchange rate, net exports, aggregate consumption, and investment for alternative model specifications. The first row reproduces the results of the benchmark simulation and the rest are for the following experiments: (1) flat, linear hazard rate, set at 28 percent for all $0 \leq t<J$ to reflect the same unconditional expectations of devaluation as the J-shaped hazard rate, (2) perfect-foresight $\left(z_{t}=0\right.$ for $0 \leq t<J$ and $z_{t}=1$ for $J-1=23$ ), (3) no adjustment in government expenditures (full rebate of the inflation tax revenue, $\eta=1$ ), (4) extended maximum durartion $(J=36)$, (5) unitary elasticity of substitution between $C^{\mathrm{T}}$ and $C^{\mathrm{N}}(\mu=0),(6)$ high labor share in nontradables $(1-\alpha \mathrm{N}=0.6)$, (7) low elasticity of substitution between $\mathrm{K}^{\mathrm{T}}$ and $\mathrm{K}^{\mathrm{N}}(\xi=-$ 0.0001), (8) high elasticity of substitution between $\mathrm{K}^{\mathrm{T}}$ and $\mathrm{K}^{\mathrm{N}}(\xi=-1)$, (9) non-zero long-run probability of success of the stabilization program $(\Pi=1 / 10$ and $1 / 2),(10)$ production with intermediate inputs, (11) high pre-stabilization money velocity ( $V=15.4$ per year, which corresponds to Mexico's M1 money balances), (12) logarithmic utility $(\sigma=1)$, and (13) inelastic labor supply $(\rho=0)$.

The results for the flat-hazard-rate case, compared to the benchmark case, show that the J-shaped $Z$ is an essential element of our analysis. The flat hazard rate produces a sustained boom for the entire duration of the currency peg, and hence cannot explain the observed cyclical dynamics and the nonlinearities of real appreciations. The sustained booms in consumption and investment produced by the flat hazard rate can be explained by studying the effects of this type of hazard rate on the tax distortions identified earlier. A flat $Z$ implies that the expected rate of depreciation, $z_{t} e$, is constant for $t=0, \ldots, J-1$. Hence, it follows from equation (21) that any variations in the currency risk premium, which governs $h(i)$ and thus the taxes defined in (22)-(24), are driven only by fluctuations in wealth (particularly the ratio $\lambda_{t+1}{ }^{H} / \mathrm{E}_{\mathrm{t}}\left[\lambda_{t+1} \mid \mathrm{e}_{\mathrm{t}}=0\right]$ ). The numerical results show that the latter induce, in turn, declining taxes on saving and investment for the entire duration of the peg. This is because every period that the peg survives increases the households' wealth by adding to permanent income the foregone government expenditures that would have been absorbed under high inflation

The above result highlights an important difference between the model examined here and the uncertain duration model of Calvo and Drazen (1998). In particular, their result that the shape of consumption dynamics is independent of the shape of the hazard rate function does not hold in our model: a flat hazard rate produces linear, upward-sloping dynamics, while a J-shaped hazard rate yields 
cyclical dynamics. Calvo and Drazen proved in a partial-equilibrium setting with incomplete markets and fiscal-induced wealth effects (and $\sigma>1$ ) that consumption always follows a strictly-increasing path for the entire duration of a tariff cut, regardless of the time path of the probability of reversal of the tariff cut. Their result follows from the fact that for any date $t$ in which the tariff cut continues, the addition to permanent income implied by foregone tariff revenue always dominates the intertemporal substitution effect implied by the fact that the expected tariff for $t+1$ is always higher than the tariff at $t$. The shape of $\mathrm{Z}$ affects the shape of equilibrium dynamics in our model because devaluation risk differs sharply from a tariff cut of uncertain duration. Uncertain duration of a tariff cut affects the timing of the reversal of the cut, but not the value of the reduced tariff while the cut is in place. In contrast, devaluation risk affects both the timing of a jump in $i$ following the switch in exchange rate regimes and the value of $i$ while the peg is in place. The latter is simply an implication of the uncovered interest parity condition under uncertainty. Our model also differs from the Calvo-Drazen framework because the generalequilibrium effects present in our model provide a channel for the shape of $Z$ to affect investment and labor, and hence the dynamics of wealth and consumption.

The perfect-foresight simulation shows that, in the absence of uncertainty, the model's dynamics are reminiscent of those displayed by deterministic credibility models. Consumption, investment, and the real exchange rate jump up on impact as the program begins, and collapse when the program ends, but for the duration of the plan they display a very gradual, linear change. Consumption and the real exchange rate both rise when the stabilization plan is introduced, but for the rest of the duration of the plan they move in opposite directions. Thus, under perfect foresight the model displays the priceconsumption puzzle. The gradual consumption boom deviates from the standard findings of Calvo (1986), but we show in Mendoza and Uribe (1997) that if the specific-factors technology is taken to the extreme that capital (labor) is a fixed factor in the production of tradables (nontradables), the perfectforesight simulation reproduces exactly Calvo's results -- despite the presence of endogenous investment with adjustment costs and despite the supply-side distortions of the transactions costs technology.

The simulation with full rebates of the inflation tax sheds light on a key element of the benchmark simulation: the state-contingent, fiscal-induced wealth effects that result from the endogenous cut in government expenditures accompanying an exchange-rate-based stabilization under incomplete 
markets. The simulation with full rebates rules out these wealth effects. The model produces cyclical dynamics qualitatively similar to those of the benchmark model, but from a quantitative standpoint one major difference emerges: the model produces a modest real appreciation that peaks at 5 percent, followed by a near full-reversal to the pre-stabilization value of $p^{N}$ if the program lasts to its maximum duration. Thus, state-contingent wealth effects are critical for explaining large real appreciations.

The values of $\mu$ and $J$ do not seem to alter the outcome of the simulations significantly -- except for the fact that $J=36$ produces a larger real appreciation and a slightly larger consumption boom than the benchmark case. The move to $1 /(1+\mu)=1$ is not a radical departure from the 0.76 elasticity in the benchmark. However, as equation (10) suggests, this elasticity has the potential for affecting significantly sectoral consumption allocations, and thus the behavior of the real exchange rate, if it were to vary more widely. For the resulting adjustment to be reflected more in $p^{N}$ than in the sectoral allocation of consumption, the change in elasticity would need to be complemented with consistent changes in the sectoral allocation of capital.

The simulation that increases the share of labor income in the nontradables sector to 0.6 , a value more in line with evidence from industrial countries, also yields results similar to the benchmark simulation except for one major change: the real exchange rate now displays the nonlinear path observed in the Mexican data, with a period of stability in between two rapid appreciations. This outcome needs to be interpreted with caution. Equation (25) implies that, everything else the same, the change in sectoral factor intensities induced by increasing 1- $\alpha \mathrm{N}$ while keeping 1- $\alpha \mathrm{T}$ constant can make $p^{N}$ increase instead of fall in the latter stages of the program. However, the change in factor intensities applies to the entire simulation period, and hence it alone cannot explain why the shape of the time path of $p^{N}$ changes only as $t$ approaches $J$. Thus, the change in factor intensities is working jointly with the frictions introduced by sector-specific capital and investment costs so that, when aggregate investment declines gradually in the latter stages of the program, it falls while increasing the ratio of $\mathrm{K}^{\mathrm{N}}$ relative to $\mathrm{K}^{\mathrm{T}}$.

The next two experiments examine alternatives of the specific-factors setup. We reduced the elasticity of substitution between $\mathrm{K}^{\mathrm{T}}$ and $\mathrm{K}^{\mathrm{N}}$ by setting $\xi=-0.0001$, compared to -0.1 in the benchmark, and tried also increasing the elasticity significantly be setting $\xi=-1$. In the first case, the reduced elasticity of substitution results in a larger real appreciation, which now peaks at around 22 percent (five 
percentage points more than in the benchmark), as equation (25) would predict. The reduced ability to shift capital across sectors also weakens the aggregate consumption boom, as the supply response of the nontradables sector in the early stages of the peg is also weakened. In the second case, with unitary elasticity of substitution, the maximum real appreciation is about 7 percent (less than $1 / 2$ that produced in the benchmark case). These results are illustrative of the key role that sector-specific factors of production play in allowing small open-economy models to explain large variations in the relative price of nontraded goods, as argued also by Uribe (1997) and Fernandez de Córdoba and Kehoe (1999).

The results of the benchmark simulation do not depend critically on the assumption that the program fails with probability 1 after 6 years. If the long-run probability of collapse after 6 years is 1 , 0.9 , or 0.5 , equilibrium dynamics before the 20th quarter are nearly identical in all three experiments, although after that date they differ markedly. This result reflects the state-contingent nature of wealth under incomplete markets. It also shows that some of the symptoms of the syndrome of exchange-ratebased stabilization may occur regardless of the long-run probability of success of the program. However, the normative predictions of the model can be significantly affected by the sharp differences in equilibrium dynamics after the 20th quarter.

The next simulation modifies the production technologies to explore the implications of incorporating intermediate inputs. This is done by following the specification proposed by Kehoe and Kehoe (1994). In particular, we use Leontieff production functions in terms of a mix of intermediate inputs and value added, while retaining the Cobb-Douglas specification to represent value added. We calibrate the model to match the observed sectoral ratios of gross production to value added in Mexico's national income accounts, and set the values of the Leontieff coefficients that measure the use of intermediate inputs in each industry using the 1989 Mexican input-output matrix (further details are available from the authors on request). This change results in a sharp decline in the size of the maximum real appreciation that the model produces (the maximum appreciation is now about 7 percent). Hence, explaining the observed real appreciation in this environment would require lowering more the elasticity of substitution between the sectoral capital stocks relative to the benchmark case. Interestingly, the model with intermediate inputs yields similar results as the scenario in which the elasticity is high. This suggests a form of equivalence in which production technologies with intermediate inputs can be 
reasonably approximated by specific-factors technologies.

The simulation calibrated to M1 velocity is motivated by the fact that while M2 is a good proxy for money balances used in transactions in Mexico, it includes some interest-bearing assets on which the inflation tax is collected at a rate smaller than the rate of inflation. Thus, the M2 specification approximates well transaction costs, but exaggerates inflation tax revenue, while the M1 specification is better at measuring inflation tax revenue but underestimates transaction costs. The simulation using M1 produces dynamics that are qualitatively similar to the benchmark case, but from a quantitative standpoint the magnitude of the booms in consumption and investment, and of the real appreciation, are now small. This occurs because the wealth effects at work using M1 are weakened considerably since government purchases now increase by a smaller amount in the devaluation state of nature (as inflation tax revenue is smaller) and the amount of resources lost to cover transactions costs is also smaller. Hence, these results show that the larger wealth effects at work in the benchmark case using M2 are critical for the model's ability to explain the magnitude of booms and real appreciations.

Changes in $\sigma$ and $\rho$, lowering the former to represent log-utility and the latter to make labor supply inelastic, alter the results mainly by enlarging the maximum real appreciation that the model can produce by 5 and 2 percentage points respectively. These two scenarios are related because changes in $\sigma$ affect both the intertemporal elasticity of substitution in consumption $(1 / \sigma)$ and the intertemporal elasticity of leisure $(1 /[1-\rho(1-\sigma)])$. The case with inelastic labor supply also weakens significantly the decline in aggregate consumption during the late stages of the peg because in this case the supply of nontradables is very slow to adjust. It can only be adjusted by changing $\mathrm{K}^{\mathrm{N}}$, which is hampered by adjustment costs in aggregate capital and by the low elasticity of substitution between capital across sectors. Hence, the general-equilibrium effects that result from endogenizing the supply of labor play an important role in allowing the benchmark model to produce recessions that predate the collapse of the currency, particularly in the nontraded sector of the economy. As a corollary, the J-shaped hazard rate is necessary but not sufficient to yield realistic business cycle dynamics.

\subsection{Welfare Implications}

Exchange-rate-based stabilization plans in the setting we examined pose a serious trade-off. On the one hand, disinflation is desirable because the initial high-inflation steady state features a high 
nominal interest rate, which embodies significant distortions on velocity, investment and labor supply note that with constant inflation, and thus constant $i$, the saving distortion vanishes. On the other hand, attempting to stabilize when agents attach some probability to the collapse of the plan introduces statecontingent, time-varying distortions on saving, investment and labor, with large wealth effects resulting from the unproductive use of government revenue. These distortions make disinflation undesirable. Hence we need to quantify the welfare implications of no stabilization vis-a-vis non-credible stabilization in order to determine whether exchange-rate-based stabilizations are worth pursuing.

Table 1 reports the welfare effects of exchange-rate-based stabilization plans under different scenarios computed using the standard compensating variation in consumption across time and states of nature suggested by Lucas (1987). Hence, we compute the percent increase in aggregate consumption in the pre-stabilization, high-inflation steady state that renders agents indifferent, in terms of expected utility, between the intertemporal allocations of $\mathrm{C}^{\mathrm{T}}, \mathrm{C}^{\mathrm{N}}$ and $\ell$ implied by a stabilization plan and those that correspond to the high-inflation status quo. Table 1 reports welfare effects for all the cases explored in the sensitivity analysis, simulating each case under perfect foresight, a flat hazard rate, and the Jshaped hazard rate of the benchmark case. Each simulation is also conducted with and without rebating inflation tax revenue to households.

Two features of these welfare calculations are important to emphasize. First, as suggested by Uribe (1999), under plausible parameter specifications, the presence of wealth and supply-side effects can make even temporary stabilizations welfare increasing. All of the simulations in Table 1 correspond to stabilization plans with a varying degree of temporariness, yet all of them produce an increase in welfare. The welfare gains range from $1 / 4$ of a percentage point to 9.2 percent, which are large figures compared to the negligible benefits of consumption stabilization reported by Lucas (1987). The welfare gains also deviate sharply from Calvo's (1988) analysis in which lack of credibility is always welfarereducing. In his setting, lack of credibility is always costly because it is identical to a temporary tax on saving at a constant rate with the proceedings fully rebated to households, in the context of a perfectforesight endowment economy. In our model, even under full rebate of the inflation tax, temporary currency pegs are preferred to continued high inflation because of the supply-side effects introduced by investment and labor supply. Of these two, the labor supply effect seems less important because the 
$-31-$

welfare gains in the inelastic labor case are similar to those of the benchmark model.

The second key welfare result is that currency risk entails very large welfare costs. In the benchmark case, an exchange-rate-based stabilization that is known to last 24 quarters with full certainty increases welfare by 5 percent, but under uncertainty with the J-shaped devaluation probabilities identified in the data the welfare gain is only 1.2 percent. A flat hazard rate results in an even smaller welfare gain at 0.88 percent. If the inflation tax is rebated to households, the perfect-foresight gain nearly halves to 2.3 percent, as the fiscal-induced wealth effect is eliminated, but the welfare gains under uncertainty are still significantly smaller (at 0.5 percent with a J-shaped hazard rate and 0.3 percent with a flat hazard rate). Thus, the implicit stochastic taxes that devaluation risk imposes on saving, investment, and labor supply are costly distortions.

\section{Concluding Remarks}

This paper shows that the risk of devaluation associated with the uncertain duration of exchangerate-based stabilization plans can produce macroeconomic dynamics roughly consistent with some of the key stylized facts of these stabilization plans. This conclusion is derived by studying the quantitative implications of a dynamic, stochastic general equilibrium model of a two-sector, small open economy with incomplete contingent-claims markets. Agents in this economy expect with some probability that an exchange-rate-based stabilization plan will be abandoned with a switch to a permanently higher rate of depreciation of the currency. Devaluation risk induces a time-variant, state-contingent premium on the domestic nominal interest rate that affects money demand and the velocity of circulation of money, and thereby induces stochastic tax-like distortions on saving, investment and the supply of labor.

The model was calibrated to Mexican data from the 1987-1994 exchange-rate-based stabilization, setting the time path of the probability of devaluation to mimic the J-shaped pattern that has been identified for Mexico and a large group of developing countries. The equilibrium dynamics of the model were then computed using an algorithm designed to solve incomplete-markets models driven by absorbent Markovian chains. The model accounts for four key features of the data: (1) booms in output and expenditures (in the aggregate and across sectors) followed by recessions that predate devaluations, (2) sizable real appreciations with a strong positive co-movement between aggregate and sectoral consumption and the real exchange rate (i.e. the price-consumption puzzle), (3) a sharp widening of the 
trade deficit followed by a reversal, and (4) a sharp fall in the velocity of circulation of money that is reversed by the time of the collapse. Under some parameter specifications, the model can also account for the observed nonlinear pattern of real appreciations, with periods of stability in between sharp appreciations.

These results differ sharply from the findings of previous quantitative studies in which lack of credibility of a currency peg could only account for a small fraction of the observed magnitude of boomrecession cycles and real appreciations, and could not explain the high positive correlation between expenditures and the real exchange rate. The cycles and the real appreciations that devaluation risk produces are 3 to 4 times larger than those obtained in previous studies. Still, the model accounts for only $1 / 2$ of the magnitude of the real appreciation observed in Mexico. VAR analysis suggests, however, that only about 40 percent of the observed real appreciation could be attributed to currency risk, in line with the model's predictions.

These results depend critically on four elements of the analysis. First, the shape of the hazard rate function that governs devaluation probabilities must follow a $\mathbf{J}$ pattern in order to produce cyclical dynamics. Second, accounting for the observed magnitude of booms in production and expenditures, and large real appreciations, requires endogenous wealth effects induced by the incompleteness of financial markets and the assumption that temporary fiscal adjustment accompanies exchange-rate-based disinflations. Third, production technologies must feature sector-specific factors of production. Without this feature, the Cobb-Douglas sectoral production functions, with nearly-identical factor intensities, that are suggested by the data produce a quasi-linear PPF for tradables and nontradables, and hence yield negligible real appreciations. Fourth, realistic cyclical co-movements, in particular recessions in the production and consumption of nontradables that predate devaluations, require supply-side effects that result from the distortions that devaluation risk induces on investment and labor supply.

The welfare implications of the model suggest that devaluation risk entails much larger welfare costs than the negligible costs of lack of credibility estimated under perfect foresight. Policies aimed at lessening the impact of the tax-like distortions induced by devaluation risk are therefore desirable. For example, if consumption tax policy is not subject to the same credibility issues as exchange-rate policy, a time-variant, state-contingent consumption tax can be useful in reversing the saving tax implicitly 
imposed by currency risk. Despite the large welfare costs of currency risk, the model's strong supply-side effects imply that stabilizations of uncertain duration are welfare-improving relative to remaining in a high-inflation equilibrium.

Further research in this area needs to focus on unifying the theory of the real effects of exchangerate-based stabilization with the theory of balance-of-payments crises, which are two research agendas that for the most part have evolved independently. One approach to develop this unified theory using the framework we examined here would be to endogenize devaluation probabilities. For example, indicators like real appreciation or foreign reserve losses, which empirical analysis has shown to be robust predictors of currency crashes, could be modeled as factors that determine the conditional probability of currency collapse. Devaluation probabilities would then be an outcome of a rational expectations equilibrium in which the dynamics of the real exchange rate and reserves influence the probability of devaluation and viceversa. Endogenous balance-of-payments crises could exist in such an environment if the setup is enriched by imposing the standard constraint on the central bank's ability to borrow foreign reserves to defend a currency peg. Mendoza and Uribe (1999) take a first step in exploring a model with some of these features with some interesting results.

We end with an important policy conclusion. Our results show that, regardless of whether exchange-rate-based stabilization plans fail or not in the long run, and even in an environment of perfect capital mobility, flexible prices, and fiscal discipline, those plans go through difficult early stages in which the exchange rate is highly overvalued and the trade deficit is large simply because agents doubt the plan will be maintained. Policy lessons must then be drawn carefully. A large trade deficit and an appreciated real exchange rate can be the result of the gradual build up of confidence on the stabilization plan (i.e., a declining monetary distortion in the context of the model we studied), and not necessarily a signal of the plan's weakness. Real overvaluation and large trade deficits are both endogenous outcomes of the equilibrium of an economy and cannot be treated as exogenous determinants of a country's ability to manage the value of its exchange rate, as is too often suggested. 


\section{References}

Aspe, Pedro (1993), Economic Transformation: The Mexican Way, MIT Press, Cambridge: MA

Blanco, Herminio, and Peter M. Garber (1986), "Recurrent Devaluation and Speculative Attacks on the Mexican Peso," Journal of Political Economy, v. 94, p. 148-166.

Calvo, Guillermo A. (1986), "Temporary Stabilization: Predetermined Exchange Rates," Journal of Political Economy, v. 94, pp.1319-1329.

, (1988), "Costly Trade Liberalizations: Durable Goods and Capital Mobility," IMF Staff Papers, v. 35, 461-473.

, (1996), Money, Exchange Rates and Output, MIT Press, Cambridge:MA.

, and Allan Drazen, (1998), "Uncertain Duration of Reform: Dynamic Implications,"

Macroeconomic Dynamics, forthcoming.

, and Enrique G. Mendoza (1996), "Mexico's Balance of Payments Crisis: A Chronicle of a

Death Foretold," Journal of International Economics, v. 41, 235-264.

Cooley, Thomas F. and Edward C. Prescott (1995), "Economic Growth and Business Cycles," in

Frontiers of Business Cycle Research, edited by T. F. Cooley, Princeton University Press, Princeton: NJ.

Dornbusch, Rudiger (1982), "Stabilization Policies in Developing Countries: What have we Learned?"

World Development, vol. 10, pp. 701-708.

Drazen, Allan and Elhanan Helpman (1987) , "Stabilization with Exchange Rate Management,"

Quarterly Journal of Economics, v. 11, 1-13.

Engel, Charles (1995), “Accounting for U.S. Real Exchange Rate Changes” NBER Working Paper No. W5394.

Feenstra, Robert C. (1986), "Functional Equivalence between Liquidity Costs and the Utility of Money," Journal of Monetary Economics, v. 17, 271-291.

Fernandez de Córdoba, Gonzalo and Timothy J. Kehoe, (1999), "Capital Flows and Real Exchange Rate Fluctuations Following Spain's Entry into the European Community," mimeo, Department of Economics, University of Minnesota.

Goldberg, Linda S. (1994), "Predicting Exchange Rate Crises: México Revisited," Journal of International Economics, v. 36, pp. 413-430.

Greenwood, Jeremy (1983), "Expectations, the Exchange Rate and the Current Account," Journal of Monetary Economics, vol. 12, pp. 543-569.

, Zvi Hercowitz, and Gregory Huffman, (1988), "Investment, Capacity Utilization, and the Real Business Cycle," American Economic Review, vol. 87, pp.402-417.

Helpman, Elhanan and Assaf Razin (1987), "Exchange Rate Management: Intertemporal Tradeoffs," American Economic Review, vol. 77, pp.107-123. 
Kamin, Steven and John H. Rogers (1996), "Monetary Policy in the End-Game to Exchange-Rate-Based Stabilizations: The Case of México," Journal of International Economics.

Kehoe, Timothy J. and Kehoe, Patrick .J. (1994), "A Primer on Static Applied General Equilibrium Models,"Federal Reserve Bank of Minneapolis Quarterly Review, Volume 18, No.1.

Kiguel, Miguel and Nissan Liviatan (1992), "The Business Cycle Associated with Exchange Rate Based Stabilization," World Bank Economic Review, vol. 6., pp. 279-305.

Kimbrough, Kent P. (1986) "The Optimum Quantity of Money Rule in the Theory of Public Finance Journal of Monetary Economics, 18(3), 277-84.

Klein, Michael W. and Nancy P. Marion, (1997) "Explaining the Duration of Exchange-Rate Pegs," Journal of Development Economics.

Kumhof, Michael, (1999), "Lower Inflation Through Lower Interest Rates - Capital Inflow Sterilization in Small Open Economies," mimeo, Stanford University.

Lahiri, Amartya, (1996), "Exchange Rate Based Stabilizations Under Real Frictions: The Role of Endogenous Labor Supply," Working Paper No. 759, Department of Economics, UCLA.

Lucas Jr., Robert E. (1987), Models of Business Cycles, Basil-Blackwell, New York.

Mendoza, Enrique G. (1995), "The Terms of Trade, the Real Exchange Rate and Economic Fluctuations," International Economic Review, vol. 36, pp. 101-137.

, and Martin Uribe (1997), "The Syndrome of Exchange-Rate-Based Stabilizations and the Uncertain Duration of Currency Pegs,"Discussion Paper No. 121, Institute for Empirical Macroeconomics, Federal Reserve Bank of Minneapolis.

and (1999), "The Business Cycle of Balance of Payments Crises: A Revision of a Mundellian Framework," forthcoming in Money, Factor Mobility and Trade: Essays in Honor of Robert A. Mundell, edited by G. A. Calvo, R. Dornbusch and M. Obstfeld, MIT Press, Cambridge: MA.

Mussa, Michael, L. (1978), "Dynamic Adjustment in the Heckscher-Ohlin-Samuelson Model," Journal of Political Economy, v. 82, pp. 1191-1203

Ostry, Jonathan D. and Carmen M. Reinhart (1992), "Private Saving and Terms of Trade Shocks; Evidence from Developing Countries," IMF Staff Papers, v. 39.

Rebelo, Sergio and Carlos A. Végh, (1996), "Real Effects of Exchange-Rate-Based Stabilization: An Analysis of Competing Theories," NBER Macro Annual, National Bureau of Economic Research, Cambridge: MA.

Reinhart Carmen M. and Carlos A. Végh (1994), "Inflation Stabilization in Chronic Inflation Countries: The Empirical Evidence," mimeo, Research Department, International Monetary Fund and (1995), "Nominal Interest Rates, Consumption Booms, and Lack of Credibility: A Quantitative Examination," Journal of Development Economics, v.46. 
Rodriguez, Carlos A. (1982), "The Argentine Stabilization Plan of December 20th," World Development, vol. 10, pp. 801-811.

Roldós, Jorge (1995), "Supply-Side Effects of Disinflation Programs," IMF Staff Papers, vol 42., pp. 158-183.

Uribe, Martín (1997), "Exchange-Rate-Based Inflation Stabilization: the Initial Real Effects of Credible Plans," Journal of Monetary Economics, June, 39(2), 197-221.

(1998a), "Habit Formation and the Dynamics of Currency Pegs," mimeo, Department of Economics, University of Pennsylvania.

(1998b), "A Log-Linear Approach to Solving the Dynamics of Currency Pegs of Uncertain Duration," mimeo, Department of Economics, University of Pennsylvania. (1999), "Comparing the Welfare Costs and the Initial Dynamics of Alternative Inflation Stabilization Policies," forthcoming Journal of Development Economics.

Végh, Carlos A. (1992), "Stopping High Inflation: An Analytical Overview," IMF Staff Papers, 39, 626695. 
Figure 1. Mexico: Real and Nominal Exchange Rates 1985-1995

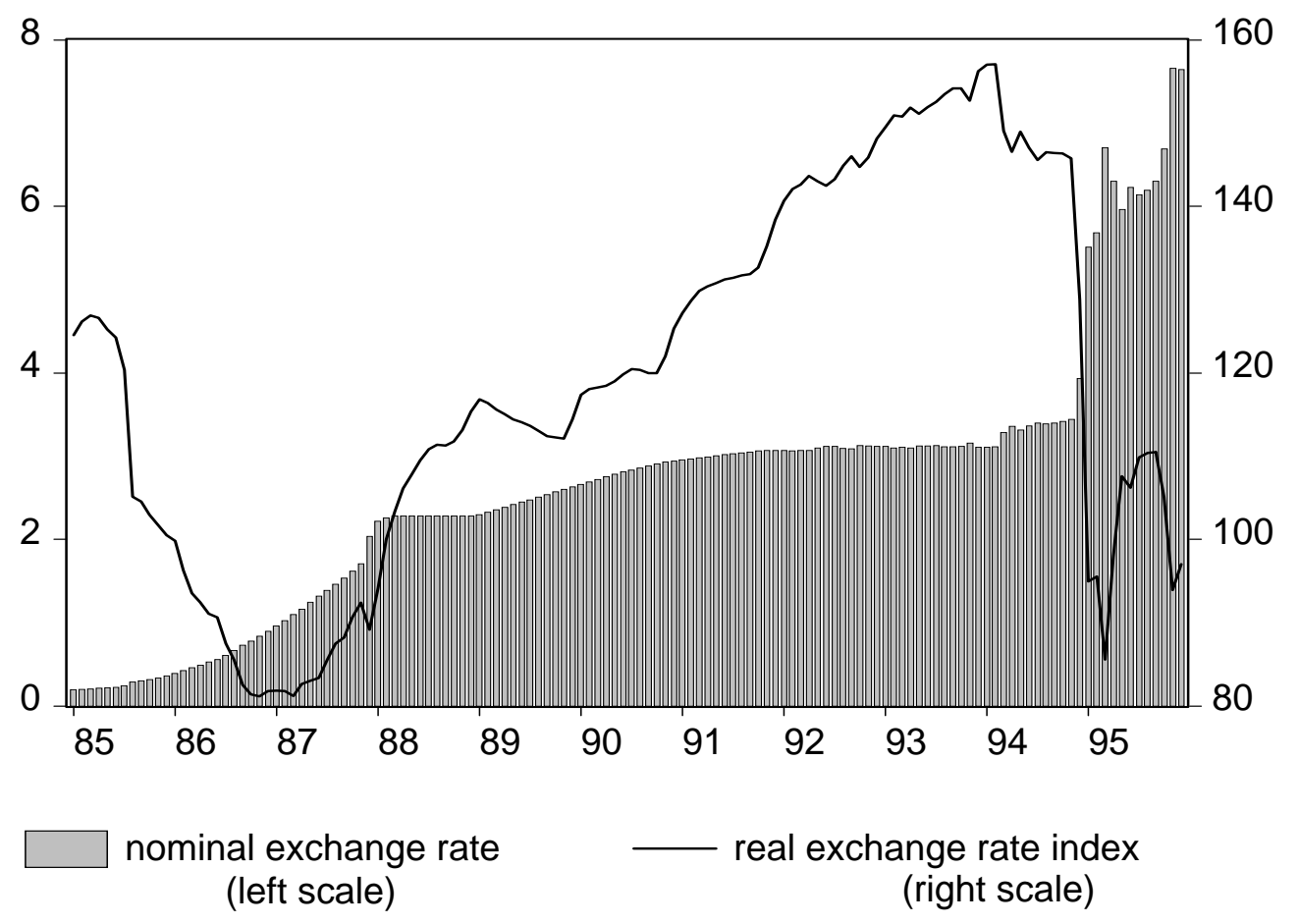

Figure 2. Mexico: Inflation Rates and Price Indexes

Twelve-month inflation rates

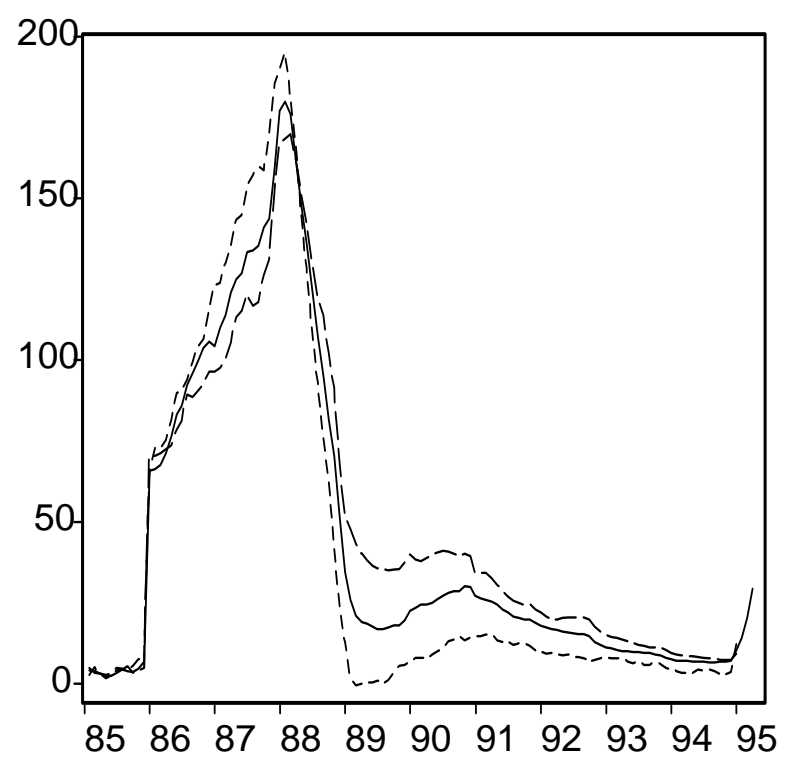

- consumer prices

---- tradables (durables)

--- nontradables (services)
Price Indexes of Tradables and Nontradbles (February 1988=100)

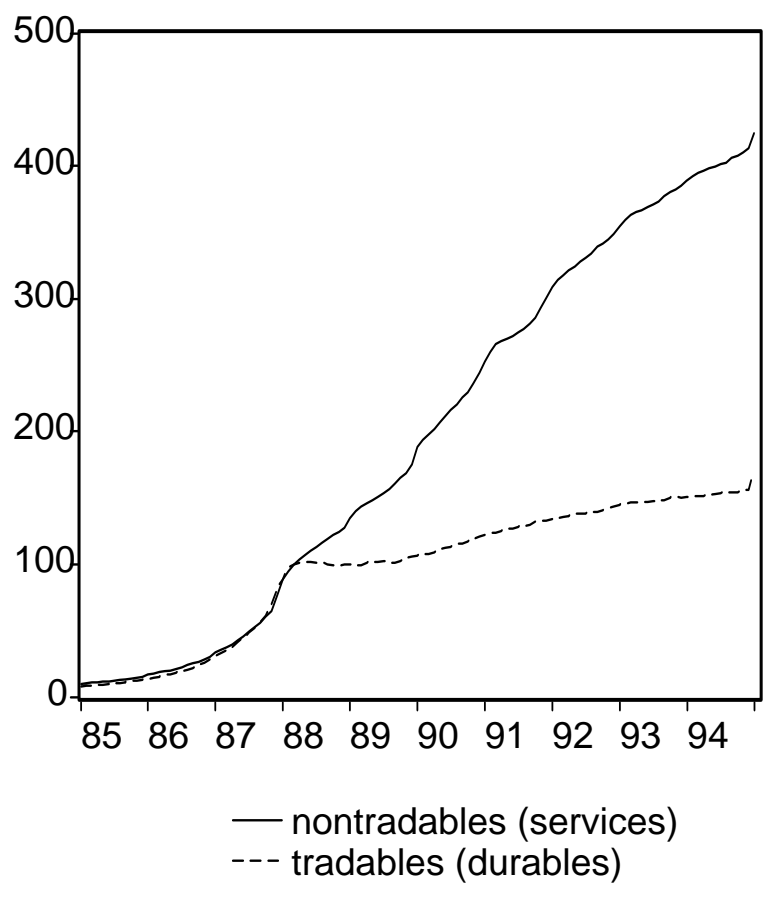


Figure 3. Mexico: Domestic Expenditures and the Real Exchange Rate
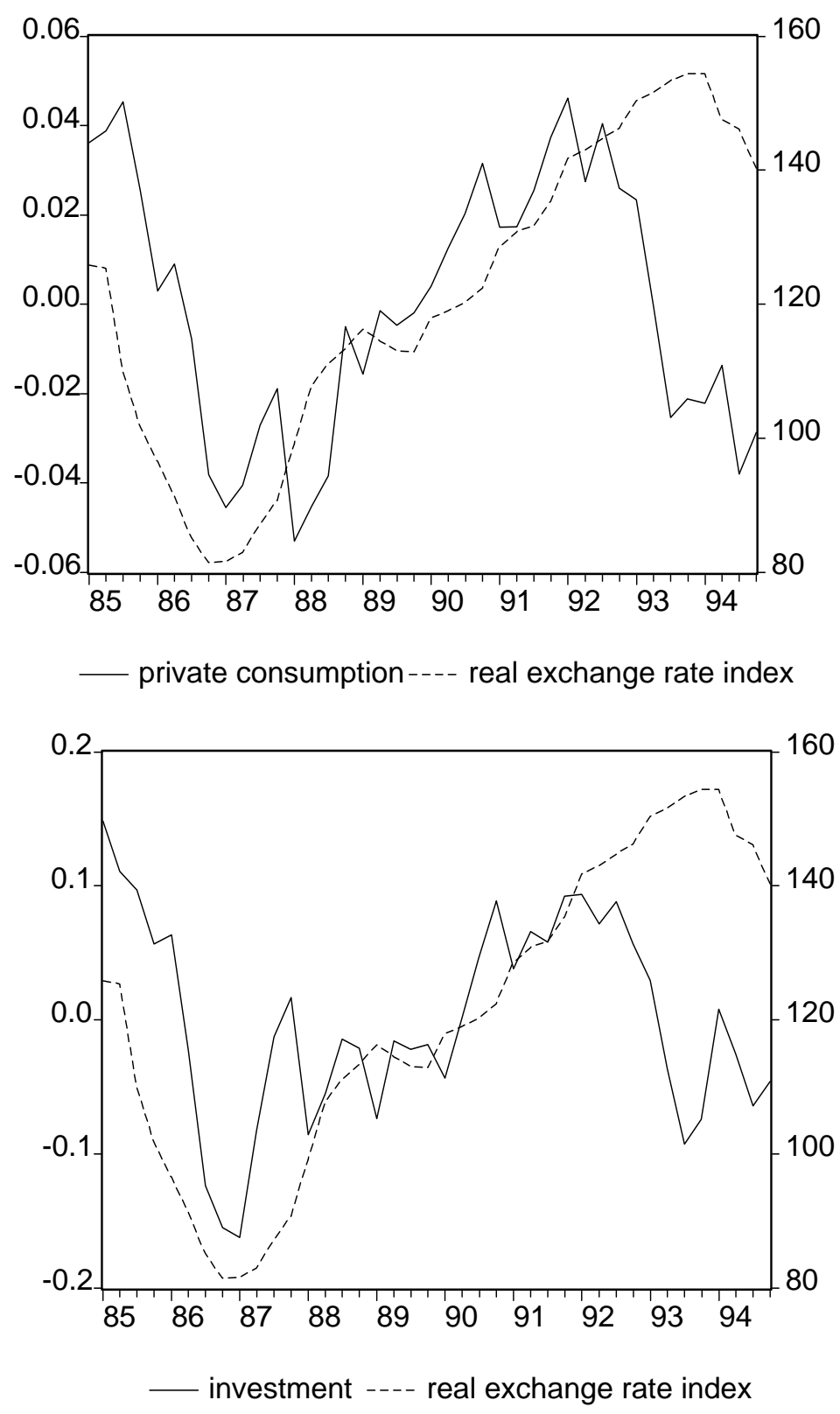

Note: Private consumption and investment are plotted in the left scale. The data were logged and detrended with a quadratic time trend. The real exchange rate index is plotted in the right scale and is calculated as the quarterly average of the monthly figures used in Figure 1. 
Figure 4. Mexico: Cyclical Components of Macroeconomic Aggregates

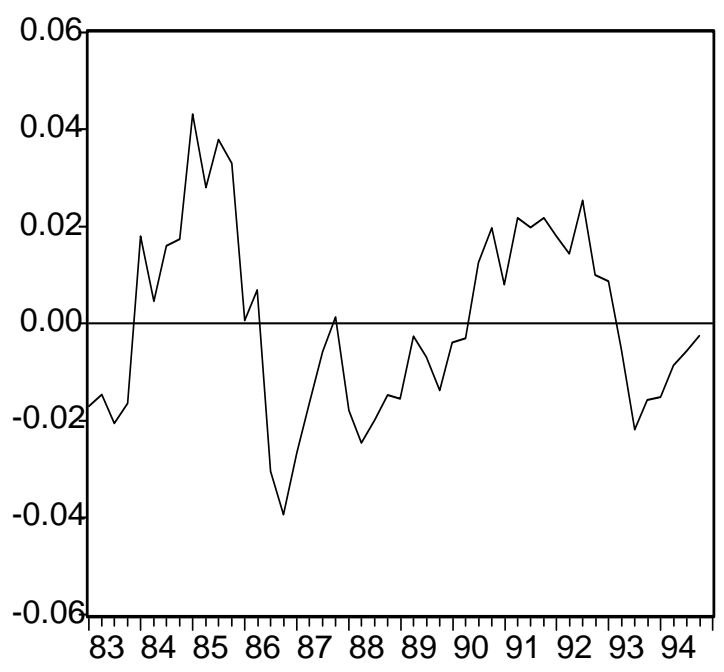

— gross domestic product

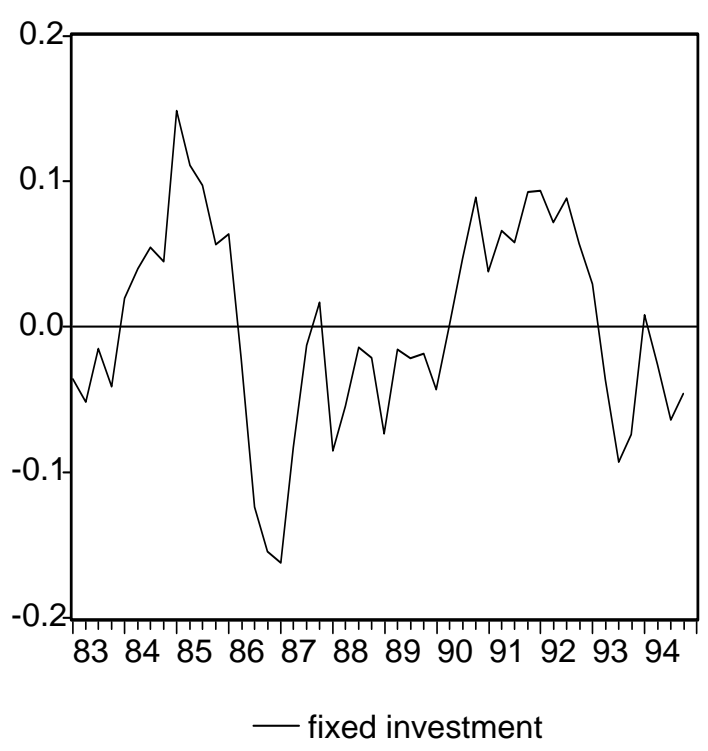

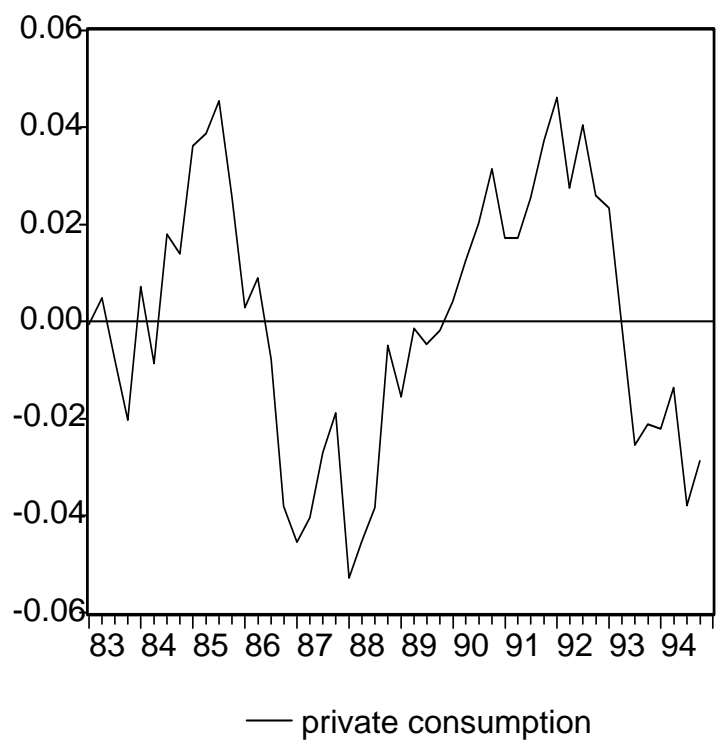

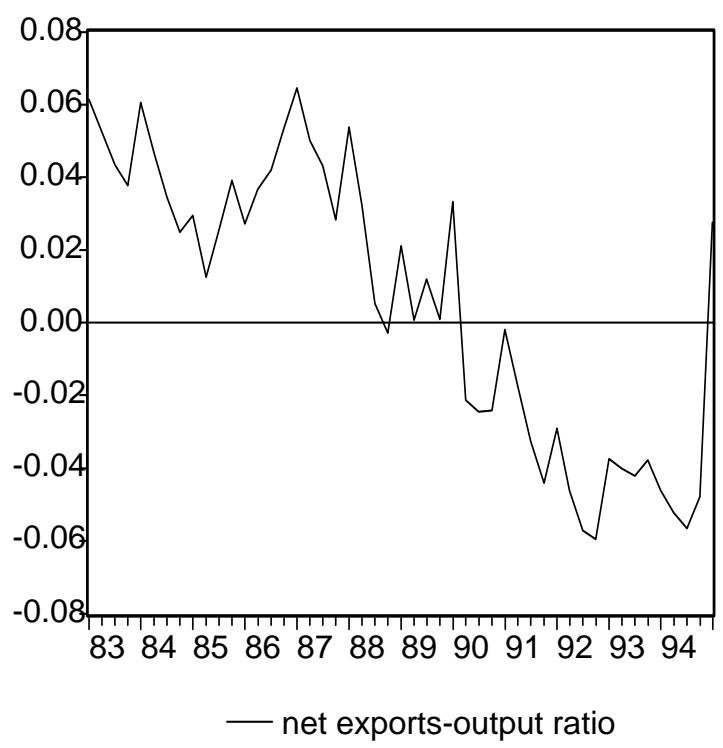

Note: GDP, consumption and investment were logged and detrended using a quadratic confirming with ADF tests that the cyclical components do not contain unit roots. The ra exports to GDP was not detrended. 
Figure 5. Mexico: Expenditure Velocity of M2

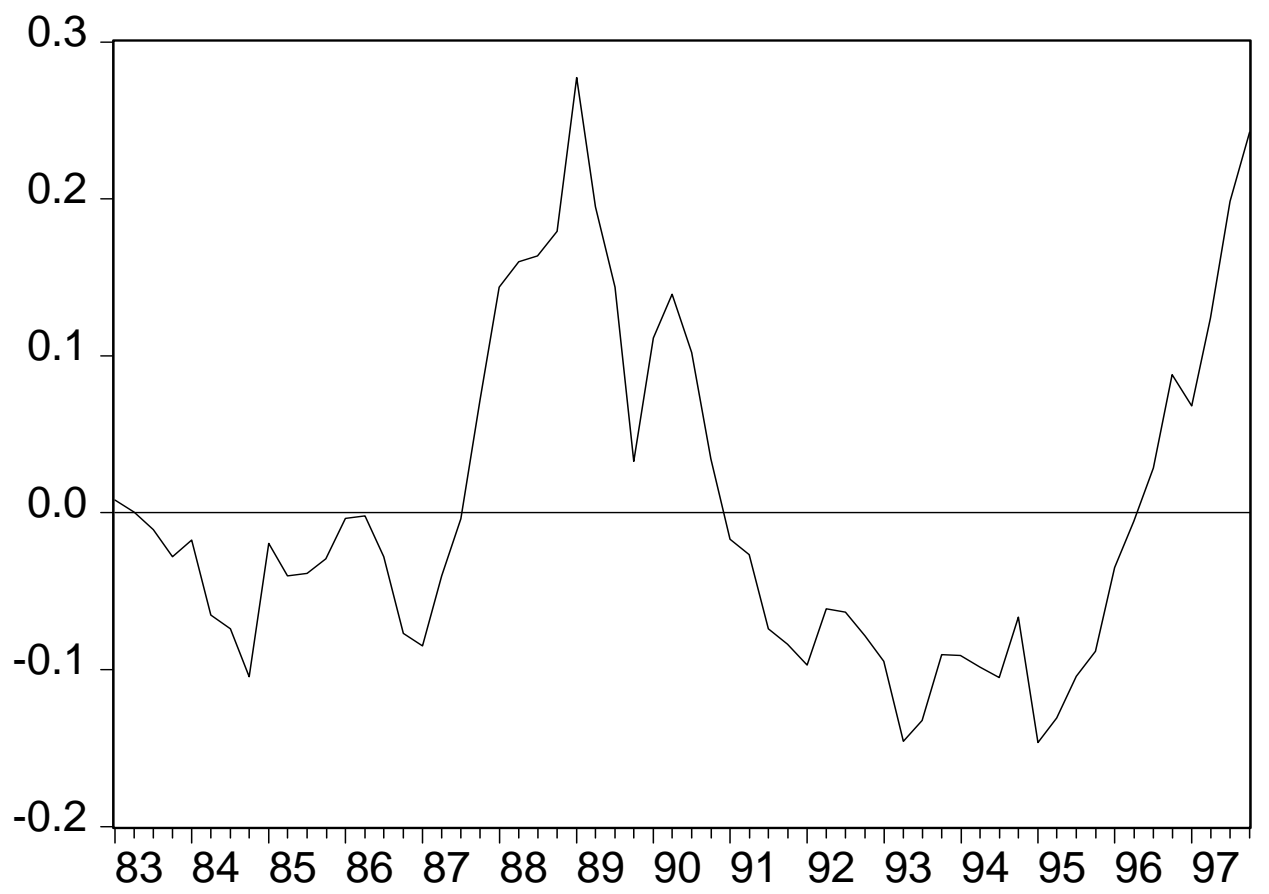

Note: Expenditure velocity is the ratio of consumption plus investment over M2 money balances. The ratio was logged, seasonally adjusted, and detrended with a quadratic trend. 
Figure 6: The Dynamics of a Currency Peg of Uncertain Duration
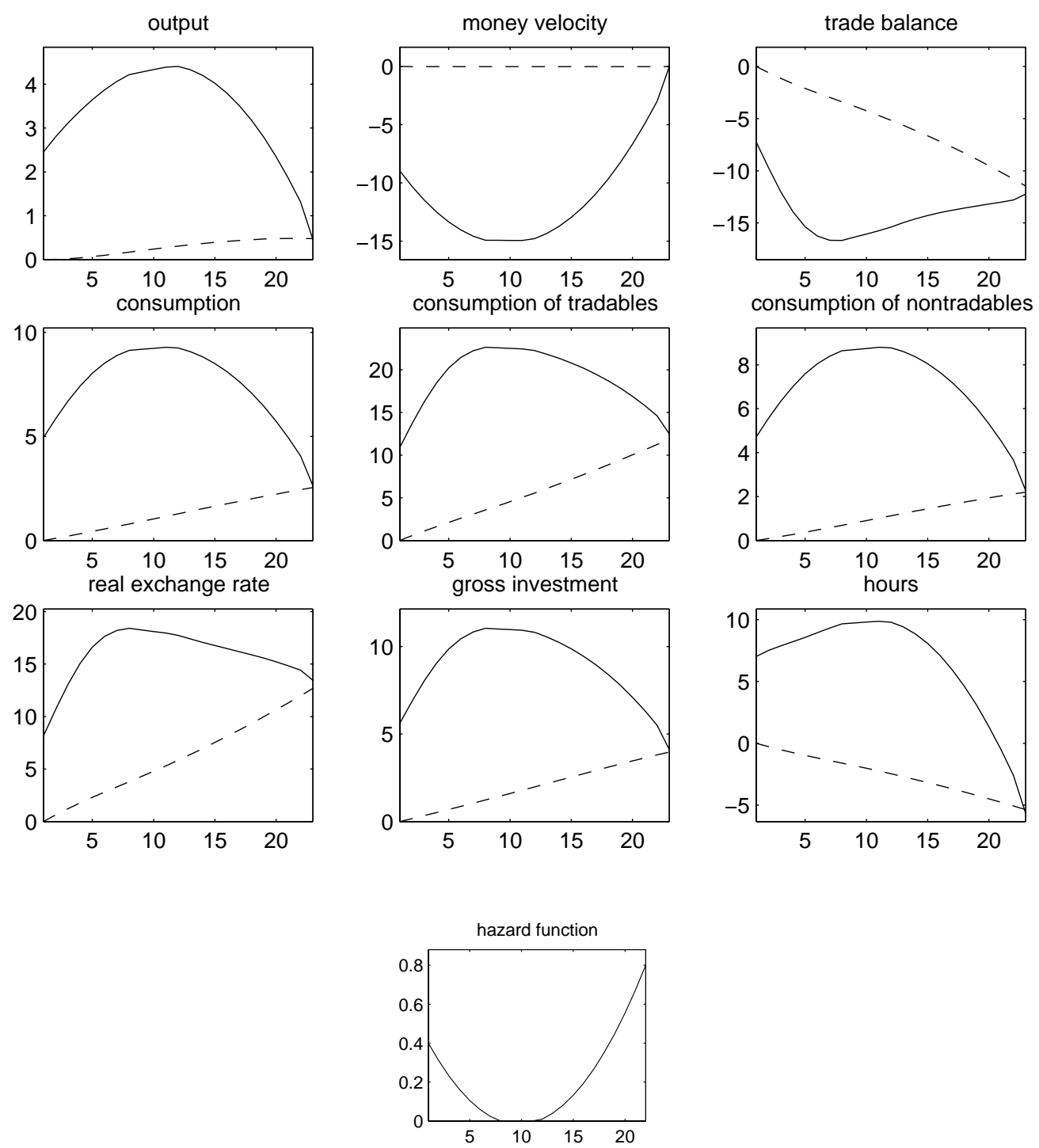

All variables, except for the hazard rate, are expressed in percentage deviations from their pre-stabilization steady-state levels. Solid lines denote pre-collapse values and broken lines denote at-collapse values. 
Figure 7: Sensitivity Analysis

The benchmark model
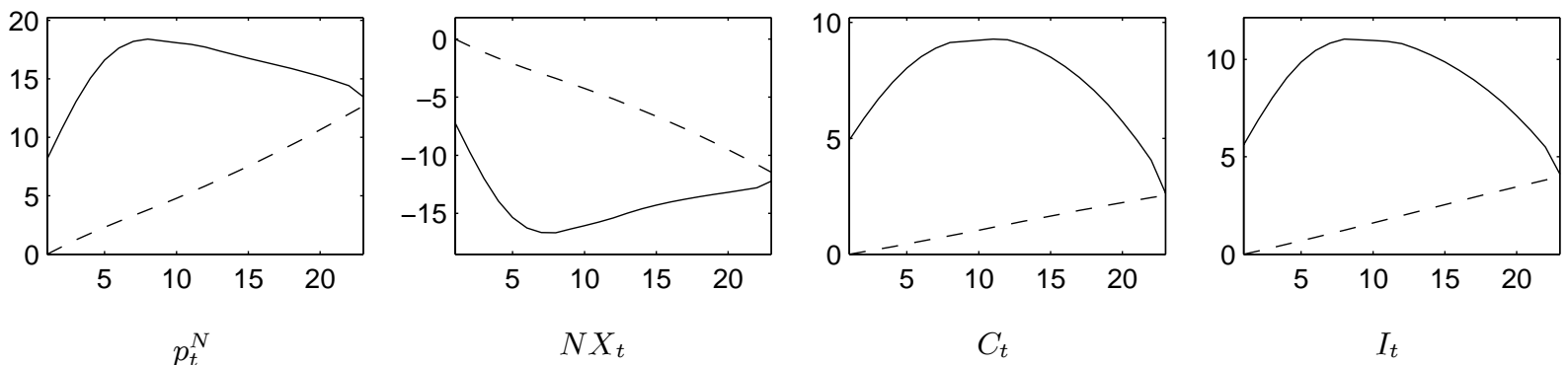

Flat hazard rate
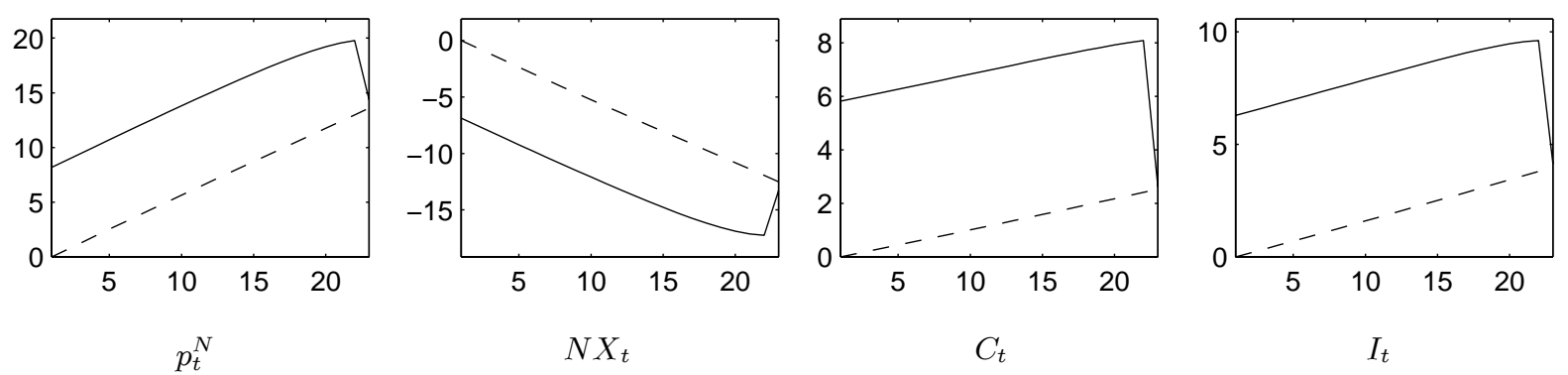

Perfect foresight
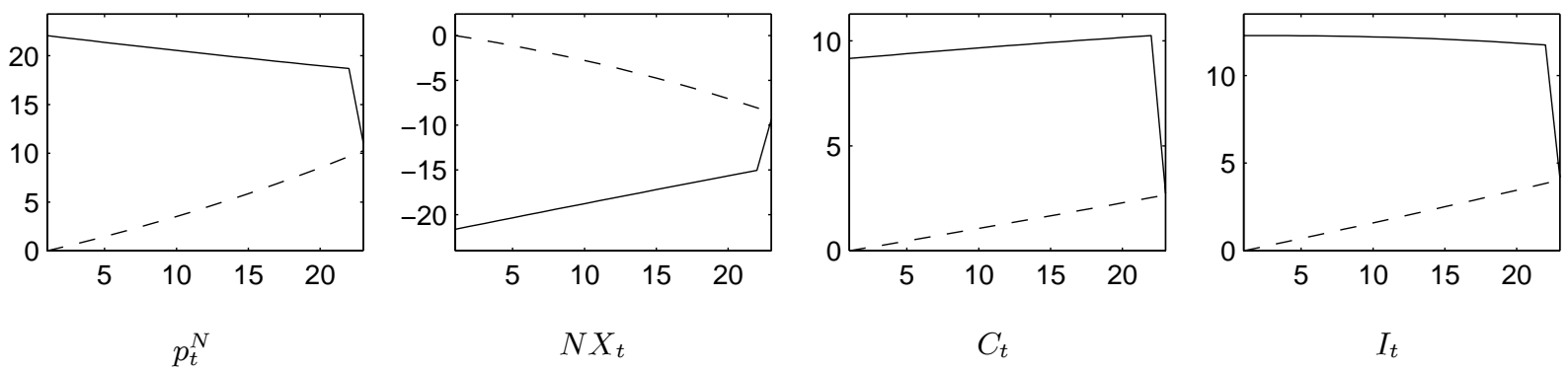

Full rebate of the inflation $\operatorname{tax}(\eta=0)$
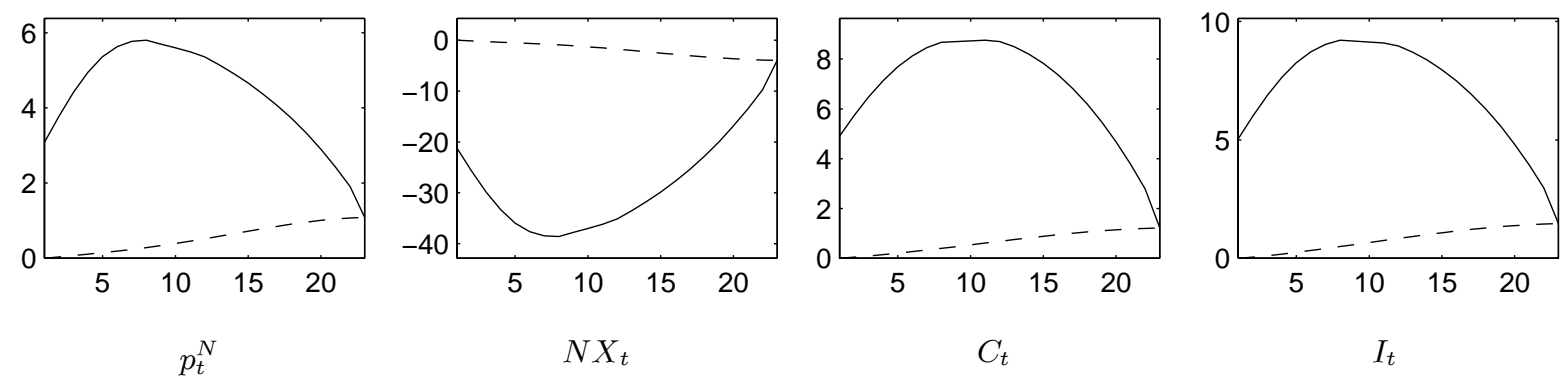

* All variables are expressed in percentage deviations from their pre-stabilization steady-state levels. Solid lines denote pre-collapse values and broken lines denote at-collapse values. 
Figure 7: continued

Extended maximum duration $(J=36)$
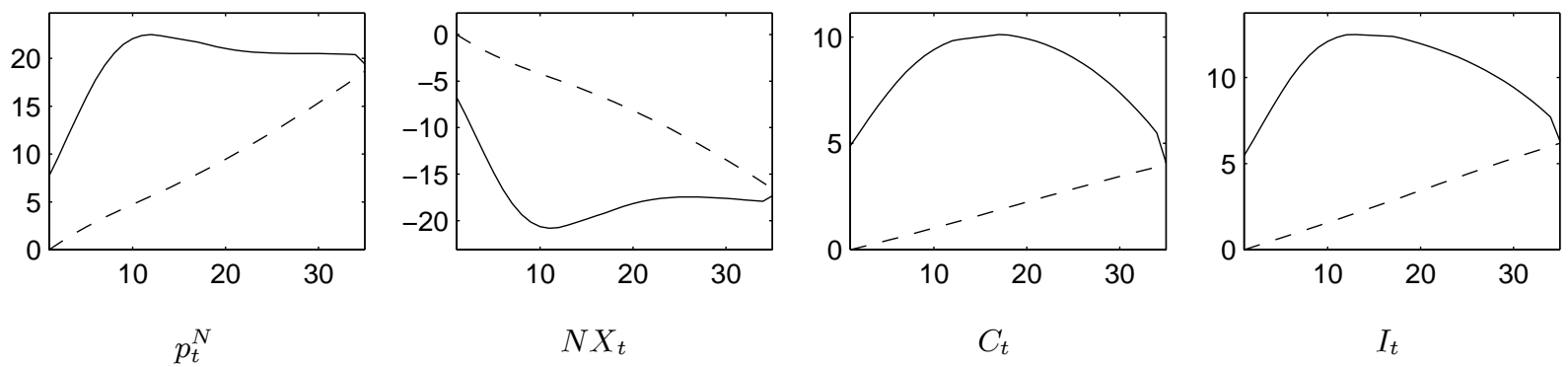

Cobb-Douglas aggregator function $(\mu=0)$
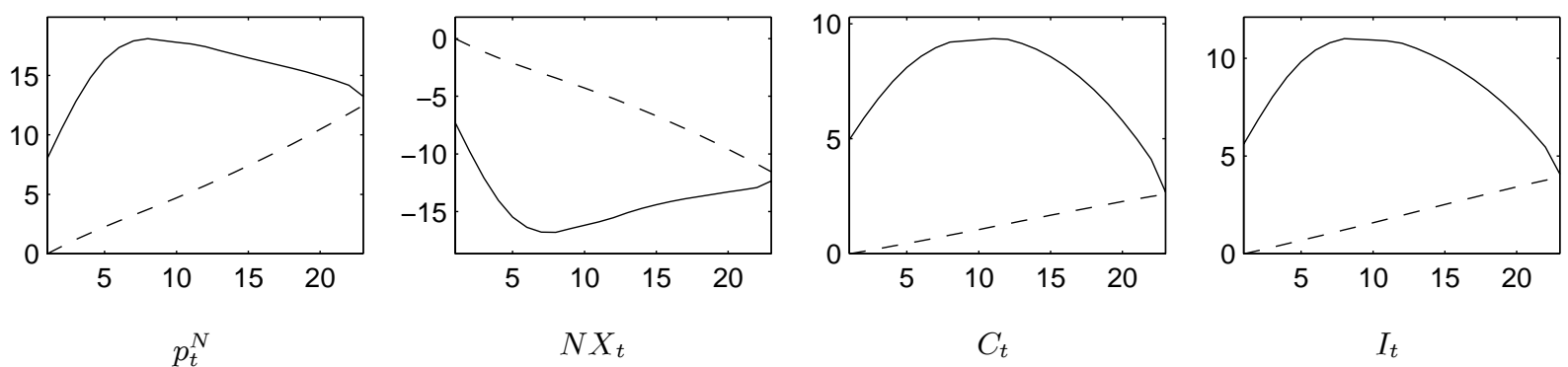

High labor share in nontradables $\left(\alpha^{N}=.6\right)$
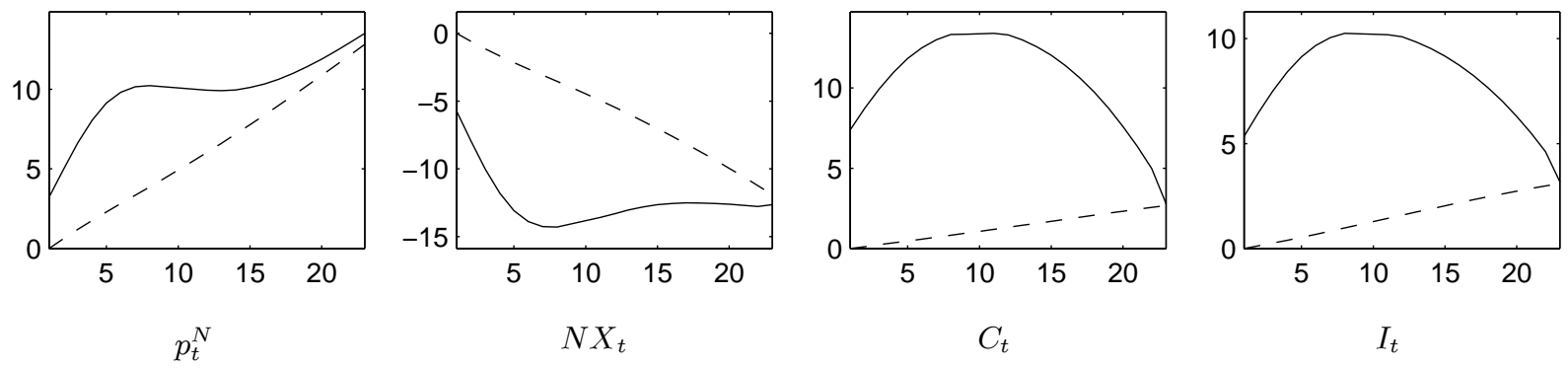

Low elasticity of substitution between traded and non-traded capital $\left(\xi=-10^{-5}\right)$
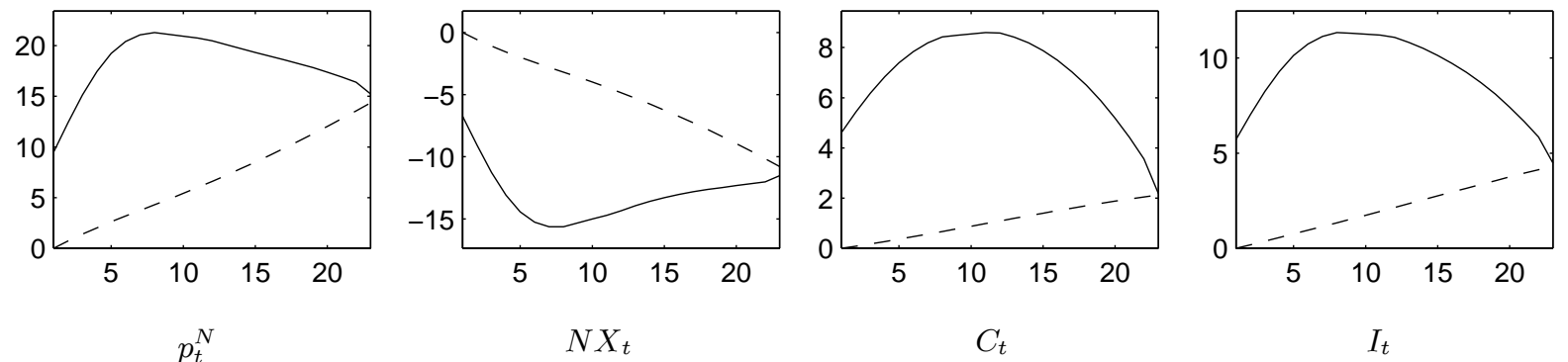
Figure 7: continued

Unitary elasticity of substitution between traded and non-traded capital $(\xi=-1)$
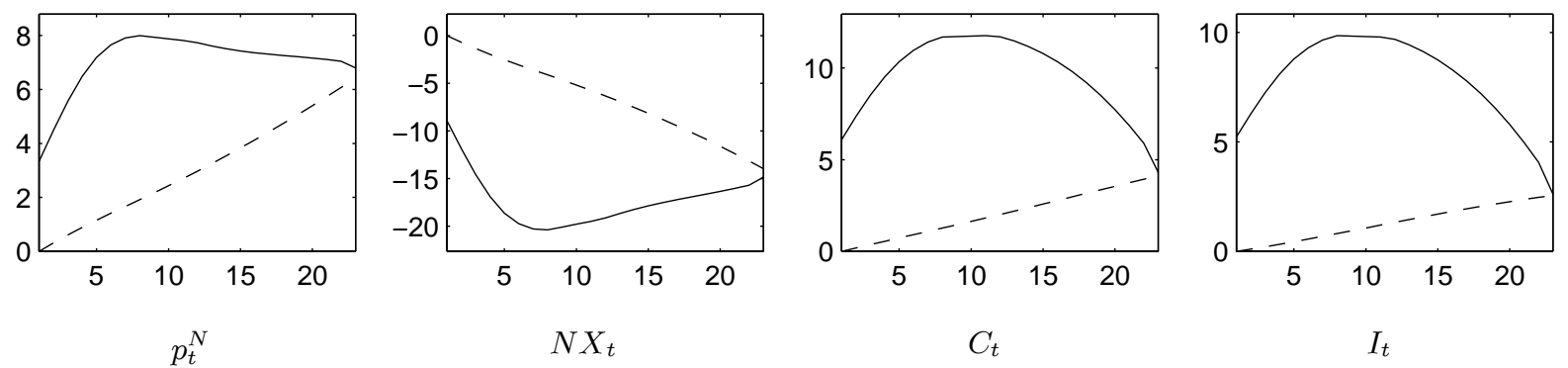

Non-zero probability of long-run success

$$
\operatorname{Pr}\left(e_{J}=e^{H} \mid e_{J-1}=e^{L}\right)=.9 \text { and } \operatorname{Pr}\left(e_{J+j}=e^{i} \mid e_{J}=e^{i}\right)=1 \text { for } i=H, L \text { and } j>1
$$
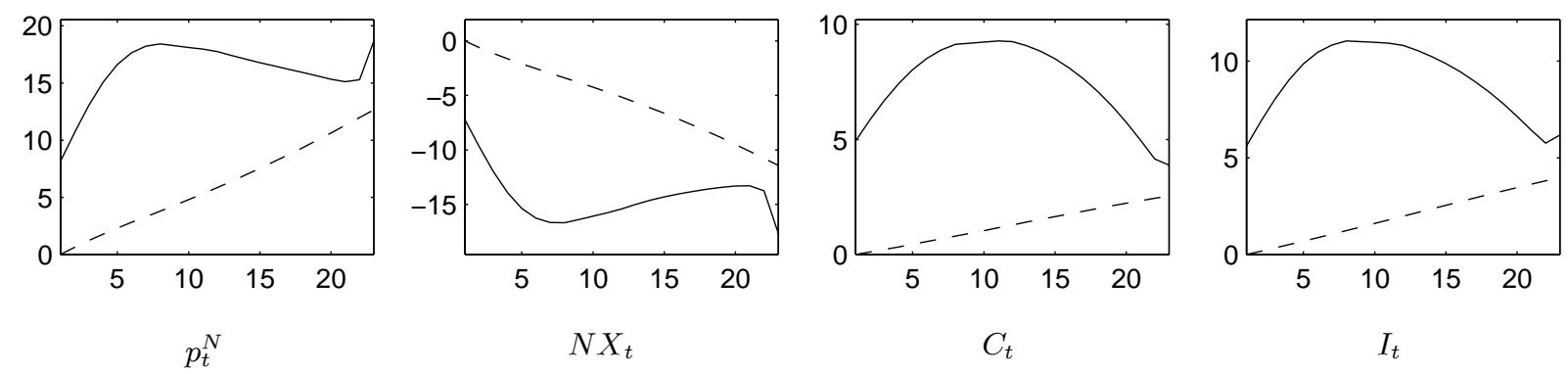

$$
\operatorname{Pr}\left(e_{J}=e^{H} \mid e_{J-1}=e^{L}\right)=.5 \text { and } \operatorname{Pr}\left(e_{J+j}=e^{i} \mid e_{J}=e^{i}\right)=1 \text { for } i=H, L \text { and } j>1
$$
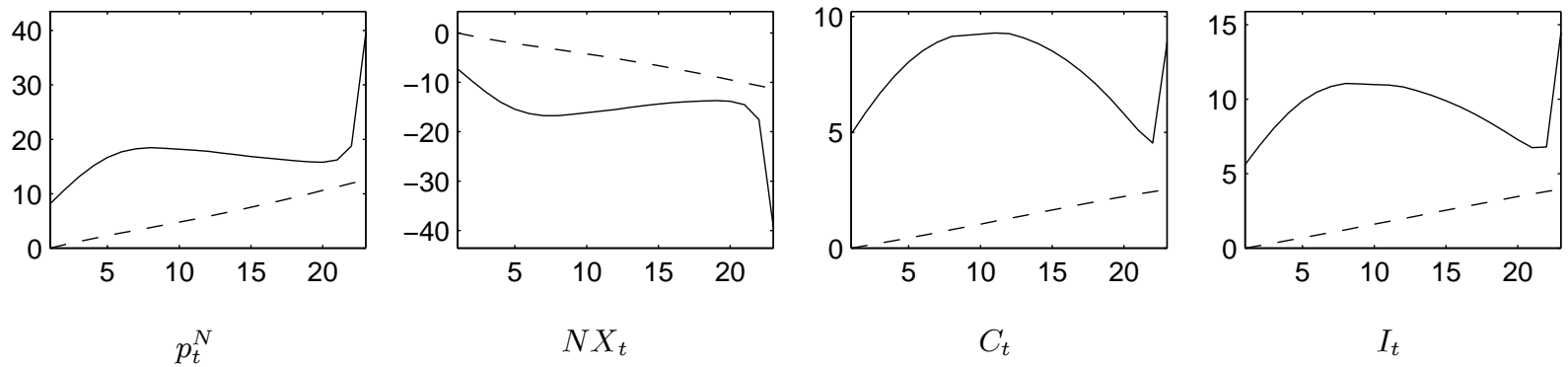

Intermediate materials
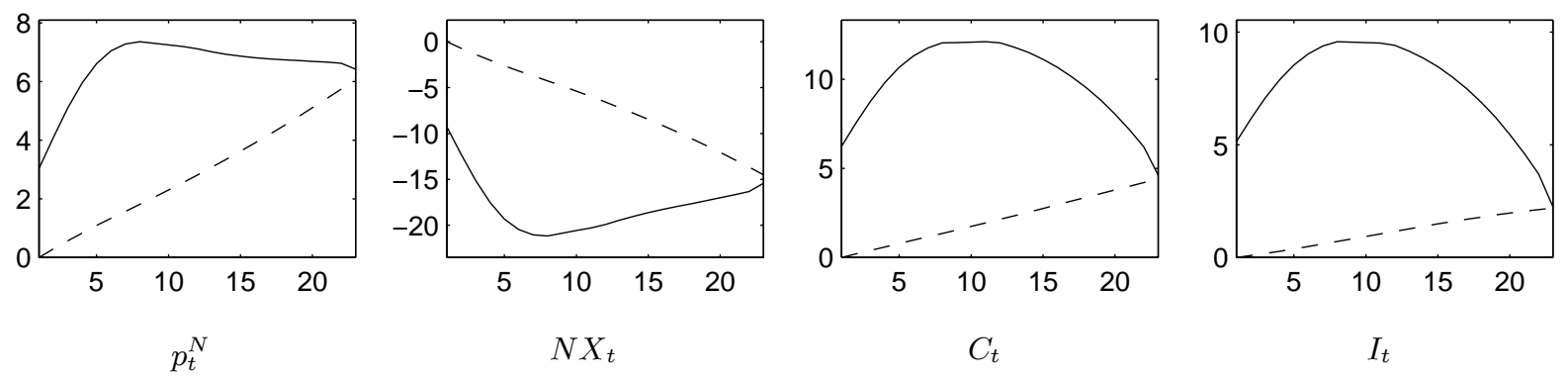
Figure 7: continued

High money velocity $\left(V^{H}=15.4\right.$ per year)
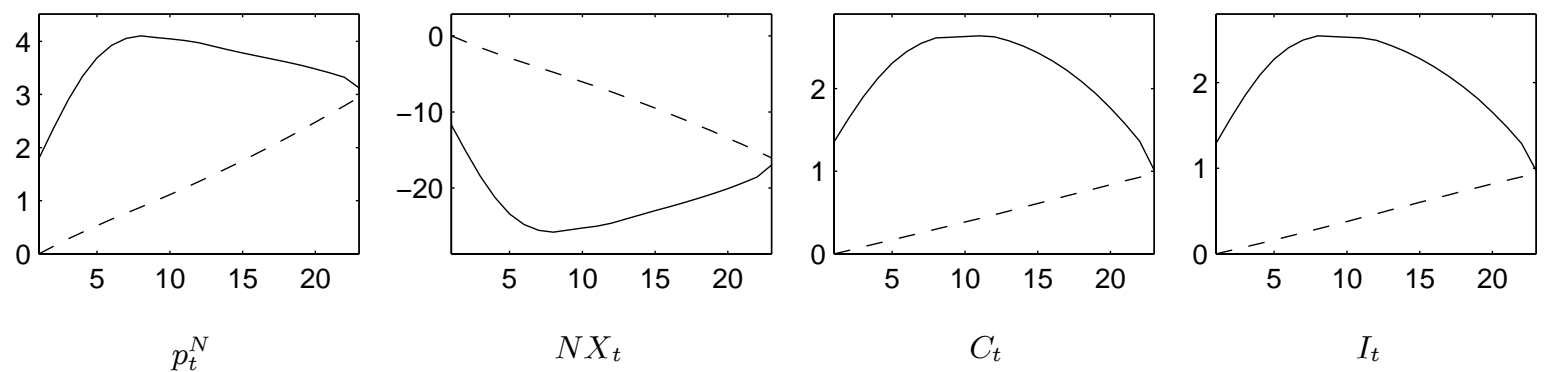

Log period utility $(\sigma=1)$
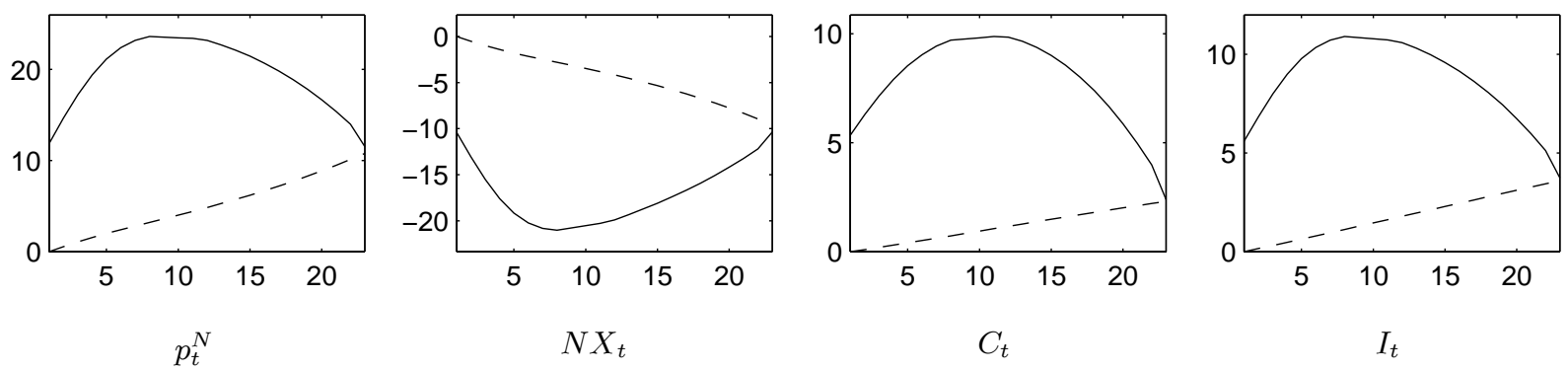

Inelastic labor supply $(\rho=0)$
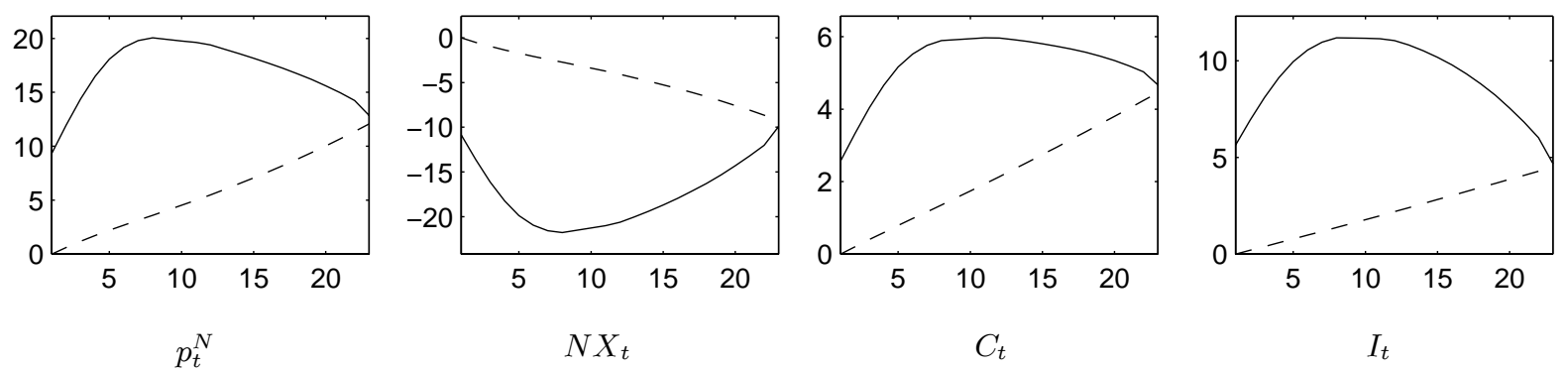
Table 1: Welfare Analysis

\begin{tabular}{|l|c|c|c|c|c|c|}
\hline \multirow{2}{*}{ Model } & \multicolumn{2}{|c|}{ Rebate of $1 / 3$ of inflation tax } & \multicolumn{3}{c|}{ Full rebate of inflation tax } \\
\cline { 2 - 7 } & $\begin{array}{c}\text { J-shaped } \\
\text { Hazard }\end{array}$ & $\begin{array}{c}\text { Flat } \\
\text { Hazard }\end{array}$ & $\begin{array}{c}\text { Perfect } \\
\text { Foresight }\end{array}$ & $\begin{array}{c}\text { J-shaped } \\
\text { Hazard }\end{array}$ & $\begin{array}{c}\text { Flat } \\
\text { Hazard }\end{array}$ & $\begin{array}{c}\text { Perfect } \\
\text { Foresight }\end{array}$ \\
\hline Benchmark & 1.17 & 0.88 & 5.06 & 0.46 & 0.31 & 2.30 \\
$J=36$ & 1.02 & 0.91 & 7.20 & 0.39 & 0.33 & 3.32 \\
$\mu=0$ & 1.13 & 0.85 & 4.88 & 0.47 & 0.32 & 2.31 \\
$s_{H N}=.6$ & 1.16 & 0.87 & 5.03 & 0.47 & 0.32 & 2.29 \\
$\xi=-10^{-5}$ & 1.03 & 0.77 & 4.42 & 0.46 & 0.31 & 2.29 \\
$\xi=-1$ & 1.72 & 1.31 & 7.56 & 0.47 & 0.32 & 2.34 \\
$z_{J-1}=.5$ & 1.17 & 0.88 & & 0.47 & 0.32 & \\
$z_{J-1}=.9$ & 1.18 & 0.88 & & 0.47 & 0.32 & \\
Materials & 1.84 & 1.40 & 8.11 & 0.48 & 0.32 & 2.35 \\
High money velocity & 2.04 & 1.56 & 9.17 & 0.46 & 0.31 & 2.30 \\
Log preferences & 1.21 & 0.89 & 5.05 & 0.47 & 0.31 & 2.28 \\
Inelastic labor supply & 1.20 & 0.90 & 5.18 & 0.39 & 0.27 & 1.95 \\
\hline
\end{tabular}

The welfare gain from a stabilization program is computed as the percentage increase in the equilibrium path of consumption under no stabilization necessary to make the representative household indifferent between stabilization and no stabilization (thus a positive number means that the program is welfare increasing). 